Florida International University FIU Digital Commons

$7-2-2013$

\title{
The Effects of Arbuscular Mycorrhizal Fungi on four Legume Hosts in South Florida Pine Rockland Soils
}

Klara Scharnagl

Florida International University, kscha005@fiu.edu

DOI: $10.25148 /$ etd.FI13080713

Follow this and additional works at: https://digitalcommons.fiu.edu/etd

Part of the Agricultural Science Commons, and the Biology Commons

\section{Recommended Citation}

Scharnagl, Klara, "The Effects of Arbuscular Mycorrhizal Fungi on four Legume Hosts in South Florida Pine Rockland Soils" (2013). FIU Electronic Theses and Dissertations. 922.

https://digitalcommons.fiu.edu/etd/922 


\title{
FLORIDA INTERNATIONAL UNIVERSITY \\ Miami, Florida
}

\section{THE EFFECTS OF ARBUSCULAR MYCORRHIZAL FUNGI ON FOUR LEGUME HOSTS IN SOUTH FLORIDA PINE ROCKLAND SOILS}

\author{
A thesis submitted in partial fulfillment of the \\ requirements for the degree of \\ MASTER OF SCIENCE \\ in \\ ENVIRONMENTAL STUDIES \\ by
}

Klara Scharnagl

2013 
To: Dean Kenneth G. Furton

College of Arts and Sciences

This thesis, written by Klara Scharnagl, and entitled The Effects of Arbuscular Mycorrhizal Fungi on Four Legume Hosts in South Florida Pine Rockland Soils, having been approved in respect to style and intellectual content, is referred to you for judgment.

We have read this thesis and recommend that it be approved.

Suzanne Koptur

Eric von Wettberg, Co-Major Professor

Krish Jayachandran, Co-Major Professor

Date of Defense: July 2, 2013

The thesis of Klara Scharnagl is approved.

Dean Kenneth G. Furton College of Arts and Sciences

Dean Lakshmi N. Reddi University Graduate School

Florida International University, 2013 


\section{ACKNOWLEDGMENTS}

I wish to thank the members of my committee for their dedication, patience, and support of my ideas. Their insight and laboratories provided me with the essential tools for the completion of my thesis. I wish to also thank the Center for Tropical Plant Conservation for the use of their shade house and garden house space for this experiment, and Joyce Maschinski, Jenn Possley, and Devon Powell for their generous donation of 100 Galactia smallii plants. I would like to thank Vanessa Sanchez, Emily Warschefsky and Daniella Vargas for their many hours of assistance with experimental design and data

collection. Finally, I would like to thank Pushpa Soti, Daria Boglaienko and Stewart Reed for their assistance with nutrient analysis.

The coursework and research experience I have received through the Master of Science track at Florida International University have been invaluable towards my career as a mycologist. I would like to thank the Fairchild Tropical Botanic Garden Graduate Student Program for the support and opportunities I have received.

Finally, I would like to thank my funding source, the United States Department of Agriculture National Needs Fellowship 2011-38420-20053, which was essential to this research, and without which I would have been unable to complete this program. 


\begin{abstract}
OF THE THESIS
THE EFFECTS OF ARBUSCULAR MYCORRHIZAL FUNGI

ON FOUR LEGUME HOSTS IN SOUTH FLORIDA PINE ROCKLAND SOILS

by

Klara Scharnagl

Florida International University, 2013

Miami, Florida

Professor Krish Jayachandran, Co-Major Professor

Professor Eric von Wettberg, Co-Major Professor
\end{abstract}

This study addressed the effects of salinity and pot size on the interaction between leguminous plant hosts and arbuscular mycorrhizal fungi in four pine rockland soils using a shade house trap-plant experiment. Little is known about the belowground diversity of pine rocklands and the interactions between aboveground and belowground biota - an increased understanding of these interactions could lead to improved land management decisions, conservation and restoration efforts. Following twelve weeks of growth, plants were measured for root and shoot dry biomass and percent colonization by arbuscular mycorrhizal fungi. Overall, arbuscular mycorrhizal fungi had positive fitness effects on the four legume species (Cajanus cajan, Chamaecrista fasciculata, Tephrosia angustissima and Abrus precatorius), improving their growth rate, shoot and root biomass; pot size influenced plant-fungal interactions; and percent colonization by arbuscular mycorrhizal fungi was influenced by soil type as well as salinity. 


\section{TABLE OF CONTENTS}

CHAPTER

PAGE

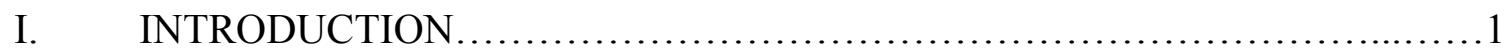

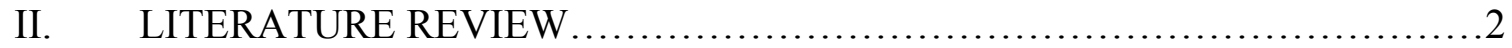

Pine Rocklands......................................................

Arbuscular Mycorrhizal Fungi............................................. 5

Soil Microbial Communities.......................................... 9

Legumes and Tripartite Symbiosis................................. 10

Global Climate Change............................................11

III. METHODOLOGY...................................................... 13

Soil Collection.......................................................

Experimental Design............................................16

Monitoring and Harvest................................................

Plant Fitness Measures...................................................21

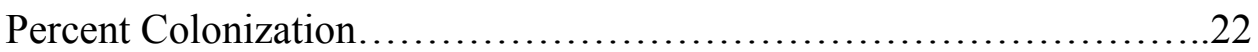

Spore Identification............................................. 24

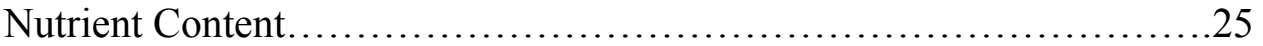

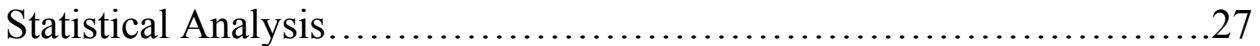

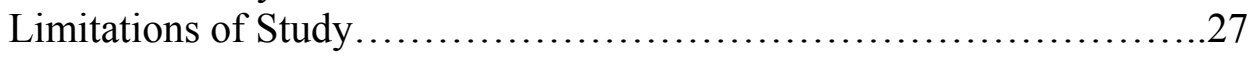

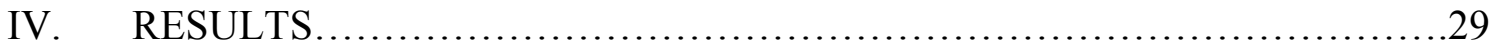

Soil Nutrients, Plant Fitness Traits and Percent Colonization............29

Differences Among Soil, Salinity Treatment, and Pot Size...............38

Diversity of Fungi by Location....................................40

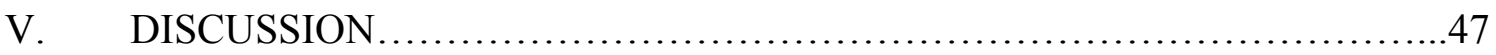

Efficacy of Arbuscular Mycorrhiza....................................47

Assessing Fitness of Symbiotic Partners.............................48

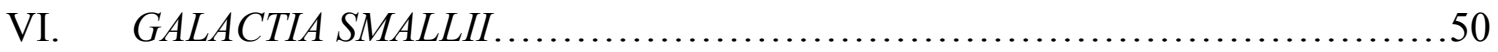

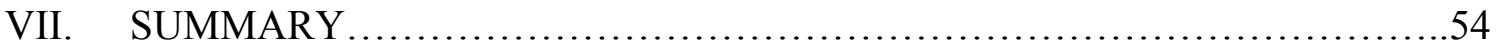

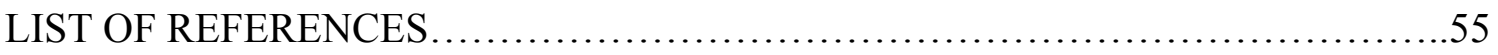




\section{LIST OF FIGURES}

FIGURE

PAGE

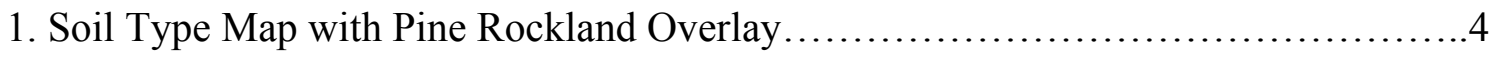

2. Image of Arbuscular Mycorrhizal Fungal Vesicle................................23

3. Image of Arbuscular Mycorrhizal Fungal Arbuscule................................24

4. Diagram of Arbuscular Mycorrhizal Fungal Morphologies.........................25

5. Soil Nutrient Content in Four Pine Rockland Locations............................29

6. Graphs of Plant Fitness Traits and Percent Colonization by Treatment [i-xii].........30

7. Pie Chart Maps of Spore Diversity

a. Generic Diversity by Location........................................41

b. Spore Texture Diversity by Location....................................44

c. Spore Color Diversity by Location...................................45

d. Spore Size Diversity by Location.....................................46

8. Shannon Diversity of AMF by Location....................................47

9. Root Tip Percent Colonization of Galactia smallii by AMF .......................52 


\section{ABBREVIATIONS AND ACRONYMS}

$\begin{array}{ll}\text { AMF } & \text { Arbuscular Mycorrhizal Fungi } \\ \text { AM } & \text { Arbuscular Mycorrhiza } \\ \text { FIU } & \text { Florida International University } \\ \text { CTPC } & \text { Center for Tropical Plant Conservation } \\ \text { BPK } & \text { Big Pine Key } \\ \text { TREC } & \text { Tropical Research and Education Center } \\ \text { HAFB } & \text { Homestead Air Force Base } \\ \text { KOH } & \text { Potassium Hydroxide } \\ \text { DI } & \text { De-ionized }\end{array}$




\section{INTRODUCTION}

This study investigated the diversity of arbuscular mycorrhizal fungi (AMF) associated with target legumes in South Florida pine rockland soils. Arbuscular mycorrhizal fungi are microbial symbionts that live in the soil and form positive mutualist relationships with plants. The role of symbionts in general has long been an understudied component of ecosystem research, yet from tropical rainforests to agroecosystems, we are finding that symbionts play a critical role (Cardoso \& Kuyper 2006, Douds Jr. \& Millner 1999). The interactions between symbionts and their hosts, or between mutualist partners, are complex (Margulis \& Sagan 1986). Symbiosis has the potential to change and shape ecosystems, to form new species, and to adapt to a changing world. It involves an elaborate interplay of chemical signals and physical interactions, often at an intracellular level. Investigation of such relationships, and the role that they play in ecosystem functioning, can greatly enhance our understanding of the parallels between symbiosis and pathogenic relationships; the complexities of gene exchange, evolution and species delineation; and organisms' abilities to adapt to major environmental stressors, such as the impacts of global climate change.

Despite the ubiquity of symbiotic relationships, little is known in this emerging field of study. Therefore, every ecosystem serves as a potential for new queries and new discoveries. In this study, I investigated the effects that AMF have on leguminous plant hosts in pine rocklands in south Florida, using a shade house experiment. I hypothesized that AMF will improve plant fitness; that AM-plants will have faster growth rates and higher dry biomass than non-AM-plants. I furthermore investigated the role that AMF play in helping their legume hosts to deal with salinity, an environmental stressor related 
to global climate change. I hypothesized that AM-plants in the salinity treatment would have higher survival rates and higher fitness measures than their non-AM-counterparts. By sampling in multiple pine rockland sites in south Florida, I also investigated the difference in AMF diversity between different locations of the same ecosystem type. Pine rocklands once covered a vast stretch of southern Florida, but since have been highly fragmented as a consequence of development, and new pine rocklands have formed outside of the original extent. I hypothesized that the AMF communities would be diverse, and that they would differ among the different pine rockland fragments, in part due to an understanding that AMF tend to have variable populations even within the same ecosystem (Treseder \& Cross 2006). Variable populations can arise from the ability of AMF to anastamose, forming complex yet single-species networks, as well as their limited ability for dispersal (sporulating directly into the soil). Furthermore, following the Intermediate Disturbance Hypothesis, different levels of environmental disturbance could impact the local AMF diversity in each pine rockland fragment.

In an additional study, I investigate the role AMF play in mature plants' ability to deal with salinity stress, by adding a salinity treatment to fifty of one hundred mature Galactia smallii plants in a shade house experiment. Galactia smallii are endemic and highly threatened pine rockland legumes; the results of this study could impact future restoration efforts. The methods and results of this study are detailed in chapter five.

\section{LITERATURE REVIEW}

\section{II-A. Pine Rocklands}

Pine rocklands are a unique dry forest ecosystem in south Florida, Cuba, and parts of the Caribbean. In south Florida, pine rocklands are dominated by Pinus elliotti var. 
densa and Serenoa repens, but are home to many other endemic, and some endangered, species of plants (FWS(I) 2000). Pine rocklands are also home to many endemic and protected species of animal, such as Puma concolor coryi and Hemiargus thomasi. Pine rocklands are important layovers along the flyway of migratory birds that pass through south Florida. Therefore they are an important ecosystem to protect. South Florida slash pine dominates the open canopy of pine rocklands, whose understory houses the majority of the diversity of these ecosystems (Lodge 2010). Pine rocklands are a fire-dependent ecosystem, whose plants are adapted to and rely upon fire. Fire helps seeds to germinate, removes invasive exotics, and returns essential nutrients to the soil. Fire is also a critical component preventing pine rocklands from converting to hammocks, another, non-firedependent ecosystem in south Florida, dominated by hardwoods (Snyder et al. 2005).

Pine rockland forests once covered a large portion of south Florida [Fig.1]. However, due to the use of pine as timber, and the higher and dryer nature of the pine rockland relative to other south Florida ecosystems, pine rocklands were highly deforested and developed. Today, pine rocklands stand at only $2 \%$ of their original extent in south Florida, and are highly fragmented (Possley et al. 2008). The largest expanse of south Florida pine rockland is protected within Everglades National Park [Fig. 1]. Many other pine rockland fragments in south Florida have been protected as local or state parks, under private ownership, or on open land. These fragments are highly vulnerable to urban encroachment, pollution and disturbance, as well as invasion by invasive exotic plants, animals, and possibly even microbes (Klironomos 2003). 


\section{ORIGINAL PINE ROCKLAND EXTENT}

WITH COLLECTION SITE OVERLAY

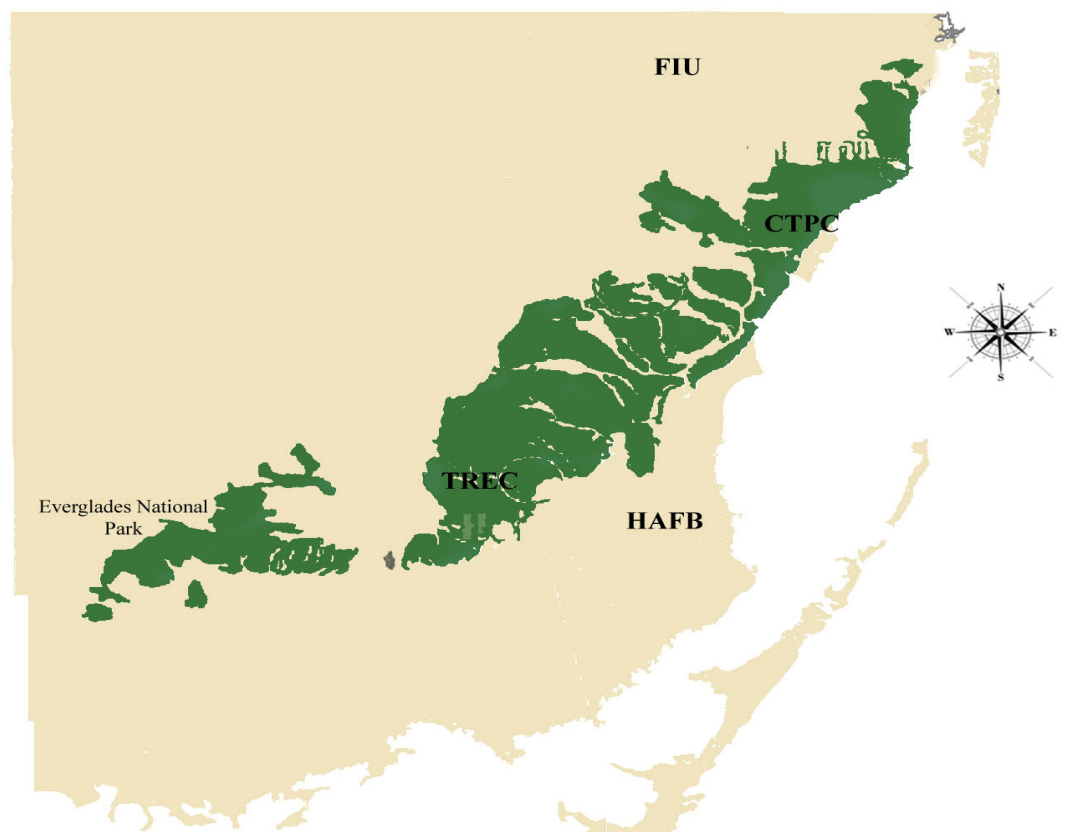

Figure 1. Map of southeast Florida showing the original extent of the pine rockland forests (Kernan 1998). Two of the four south Florida sites for this study are within the original pine rockland extent [TREC, CTPC]. Everglades National Park is also depicted to show the large patch of pine rockland still protected there.

Most pine rockland fragments in urban areas cannot be burned because of the danger burning would pose for nearby houses and other structures. Therefore, invasive species, or even native species that would cause succession from pine rockland to hardwood hammock, have to be removed manually. There are current initiatives, such as the 'Connect-to-Protect' program, to restore and connect (via intermediate plantings of pine rockland native plants) the small fragments of remaining pine rockland that are scattered throughout the south Florida urban landscape (DERM 2004, Maschinski 2013). Much research has gone into how to restore, protect and maintain species diversity in these imperiled ecosystems. Despite an ever-growing knowledge of the aboveground 
biodiversity in pine rocklands, far less is known about the belowground, soil communities. While the trees in pine rocklands, such as Pinus elliotti, associate with ectomycorrhizal fungi, much of the other flora in pine rocklands associate with AMF. A better understanding of the role that AMF play in the survival and growth of pine rockland plant species could lead to initiatives to inoculate pine rockland restoration areas with AMF spores that will associate with native plant species (Fisher \& Jayachandran 2002, Jayachandran \& Fisher 2008). It could also lead to a better understanding of the role soil microbes such as AMF play in the successful establishment of invasive exotics, and this information could be used in removing and combating these invasive exotic species (Klironomos 2003).

\section{II-B. Arbuscular Mycorrhizal Fungi}

Arbuscular myocrrhizal fungi (AMF) are microscopic fungi that dwell entirely in the soil. They are considered obligate symbionts to plants; that is, they cannot survive nor reproduce without being associated with a plant host. Arbuscular mycorrhizal fungi associate with over $80 \%$ of land plants, and ancestrally AMF may have played a critical role in plants' first colonization of land (Denison \& Kiers 2011). Thus the symbiotic relationship is not only ubiquitous but is evolutionarily ancient. Arbuscular mycorrhizal fungi associate directly with plant roots: also known as endomycorrhizal fungi, their hyphae actually penetrate plant cells and the symbiotic exchange takes place within plant cells in the growing part of the plant roots. The specific association between a plant root and an arbuscular mycorrhizal fungus is called the arbuscular mycorrhiza, or AM symbiosis. Until recently, on the basis of spore morphology coupled with a lack of contextual research, it was believed that AMF were generalists, and that AMF could 
associate with a variety of plant hosts in the same way, providing the same benefits. Through molecular analysis and an increase in ecological research in the AM symbiosis, we now know that AMF are not as generalist as presupposed, and that each specific AM fungus-plant pairing can have radically different effects on both the plant and the AM fungus (Kivlin et al. 2011). Arbuscular mycorrhizal fungi are members of the fungal phylum Glomeromycota. They are distinct from other lineages of fungi, and are divided into the Glomerales, Diversisporales, Archaesporales and Paraglomerales.

Glomeromycota currently consists of approximately 150 species, though it is estimated that there are many more, which will be discovered through more in depth molecular and ecological research (Schüßler et al. 2001).

Some AMF have come to be known as 'cheaters' - that is, fungi that take more than they receive within the symbiotic exchange, or fungi that trick the plant into giving up its share without providing any return (Sanders 2003). Some plants have built in adaptations to control these 'cheaters,' by cutting off supplies to the cells occupied by the fungi and thus ending the symbiosis. A cutting-off of the symbiosis can also occur simply when the plant no longer needs the fungal associate, as in high available-nutrient conditions. There are converse examples of plant exploitation of AMF, such as orchid fungi and mycotrophs such as Monotropa uniflora. The AM symbiosis, therefore, is a unique and context-dependent relationship (Kiers et al. 2011). Much more research is needed to investigate the many possible contexts and relationships that AMF can have (Feddermann et al. 2010).

The AM symbiosis often begins with a spore in the soil. When moisture is sufficient, the spore will germinate, and begin to travel through the soil, seeking a plant 
host. How an AM fungus seeks a plant host is likely through a chemical gradient coming from the plant roots, a combination of strigolactones and other signals (Bonfante \& Genre 2010). If the spore does not find an adequate host quickly, it can actually retract its hyphae, and re-enter a dormant stage until trying again. In the instance that an adequate plant host is in the vicinity of the germinating spore, the AM fungus releases its own cocktail of chemical signals, including a lypochitooligosaccharide called the Myc factor (Maillet et al. 2011). The Myc factor acts as a sort of announcement of identification. If it is determined, via back and forth signaling, that the plant and fungus are compatible, the plant will form a pre-penetration pathway through which the AM fungus can begin to enter the plant cell space ${ }^{1}$. The hyphae of the AM fungus make their way to the inner layer of plant cells in the growing root tip, or area of active exchange. There, the hyphal terminus will enter a plant cell space, the plant cell's cytoplasm will move over to allow the fungus to enter, and the fungal and plant cells will have direct membrane exchange of nutrients and photosynthates, or sugars. The typical form that this fungal membrane exchange apparatus takes is a branched structure called an arbuscule, which maximizes the surface area for exchange. As the plant root grows, the AM symbiosis, particularly the area of active exchange, moves along with the growing root tip (Bonfante \& Genre 2010). Some AMF release a hormone that promotes plant root growth, a somewhat selfserving act, as it then provides the fungus with more areas to associate with the plant and therefore receive carbon for growth. However, this increase in carbon to the fungus enables the fungus to grow and reach nutrients even further into the soil, benefiting the

\footnotetext{
1 This pre-penetration pathway distinguishes the AM relationship as a positive symbiotic relationship, as opposed to pathogenic fungi that would enter the plant root by force, using a pressurized structure known as an appressorium.
} 
plant. Though the details of the chemical communication are still being discovered, it is known that the plant host and the AM fungus are in constant communication throughout the AM symbiosis. AMF and plants are in constant dialogue not only at the individual symbiosis level, but throughout their mutual evolution, influencing one another's ability to adapt and survive (Bonfante \& Genre 2008, Hausmann \& Hawkes 2009, Ercolin \& Reinhardt 2011).

The AM symbiosis, from the plant host's perspective, can begin shortly after germination, can perpetuate throughout a plant's lifetime, can switch between different AMF communities or even switch from AMF communities to ectomycorrhizal associations, or can be cut off when the AMF are no longer needed. In contexts such as agriculture, where soil is not inundated with fungicide, AM associations still tend to be minimal or absent as a result of the large amounts of phosphorus fertilizer added to the soil. Most crop plants have not been bred for symbiotic associations and have as a consequence become very un-regulating generalist hosts of AMF, which has the advantage of enabling crop plants to associate with, and benefit from, a wide variety of AMF species, however it can also make crop plants more susceptible to 'cheater' species. The generalist nature of most crop plant hosts should be considered as AMF are incorporated into sustainable and organic agricultural practices (Gosling et al. 2006). When a plant is in optimal soil conditions [plenty of water and available nutrients] there is no need for the plant to associate with AMF. However, in most natural contexts, nutrients, water or both may be limiting and therefore plants often associate with AMF. Specifically, arbuscular mycorrhizal fungi use their long threadlike hyphae to explore the soil for nutrients that would otherwise be inaccessible to plants. The main nutrient 
provided by the AM fungus to the plant is phosphorus, however, AMF are also know to provide plants with nitrogen, as well as essential micronutrients such as magnesium and zinc (Friesen et al. 2011).

There are many other benefits conferred by AMF that are not directly associated with the exchange of nutrients. By sending their hyphae through the soil, they create channels through the soil for water, air and other microorganisms to use, creating a healthier overall soil ecosystem. In addition, AMF have been found to be associated with the production of glomalin, a glycoprotein that acts as a sticky substance, creating aggregates, which are considered a sign of a healthy soil (Rillig et al. 2003). Though the mechanisms are less known, AMF have also been shown to help plants deal with a variety of environmental stressors, including drought, flooding, soilborne pathogens, heavy metals, and salinity (Wehner et al. 2010, Khan et al. 2010, Hildebrandt et al. 2007, Sah et al. 2006). Through nutrient exchange, AMF participate in several nutrient cycles, including micronutrient cycles. Arbuscular mycorrhizal fungal hyphae act as extensions of plant roots. As such, they not only participate in nutrient acquisition for the plant, they also, like fiber optic cables of the forest, transmit signals, from parental to offspring plants, from parasitic to host plants, or as a participant in allelopathy (Babikova et al. 2013). AMF form elaborate networks in the soil, performing a wide variety of ecosystem functions, some of which we may not have yet discovered.

\section{II-C. Soil Microbial Communities}

Soil is comprised of far more than arbuscular mycorrhizal fungi. A whole consortium of fungi, bacteria and other microscopic organisms are associated with the rhizosphere, that is, the area around plant roots (Doran \& Zeiss 2000). Some are 
beneficial, even symbiotic, with the plant. Others are neutral, perhaps gaining some secondary benefit without any cost to the plant. Others still can be parasitic, gleaning benefits from other rhizosphere organisms or from the plant without providing any return. These complex communities are themselves one small component of the total soil community. Looking beyond the rhizosphere is like looking over the drop-off point from a coral reef. It is the abyss of knowledge; soil is considered the final frontier of discovery, and there is immense biodiversity still to be discovered therein (Amundson et al. 2003).

Even within arbuscular mycorrhizal fungi is a complex microbial community. Arbuscular mycorrhizal fungi are home to a variety of endobacteria, whose function is little known but may be involved in the creation of some of the complex chemicals used in signaling during the AM symbiosis. There are multiple types of 'helper bacteria' in the rhizosphere also involved in the steps leading up to the AM symbiosis (Miransari 2011, Rillig et al. 2005, Tarkka \& Frey-Klett 2008). Plant hosts would not be able to get many nutrients from their AMF associations without a large diversity of saprotrophs in the soil. Arbuscular mycorrhizal fungi are a critical yet little understood component of the brown food web (Kaspari \& Yanoviak 2009). An increased understanding of the diversity and ecology of AMF will lead to a greater understanding of soil ecology.

\section{II-D. Legumes and Tripartite Symbiosis}

Legumes are unique plants in that they make associations with both AMF and rhizobial bacteria. They are members of a tripartite symbiosis (Mortimer et al. 2008). As such, they are ideal organisms for the study of the impacts of symbionts on the host and the impacts of environmental changes on the symbiotic relationship (Chalk et al. 2006, Sprent \& James 2007, Albrecht et al. 1999). When AMF associate with non-leguminous 
plants, they often provide nitrogen in addition to phosphorus from the soil. However, for legumes, rhizobial bacteria fix and provide nitrogen to the host plant, thus enabling the AMF to focus on phosphorus and other micronutrient uptake. There are interesting parallels between the signaling and activity associated with the rhizobial and the AM symbiosis, including the similarity between the Nod factors used by rhizobial bacteria and Myc factors used by arbuscular mycorrhizal fungi. These similarities in symbiosis could be a result of a limited number of symbiosis channels in plants, or could imply a coevolutionary history (Oláh et al. 2005).

The tripartite symbiosis of certain legumes make them interesting study subjects, but the complexity of the tripartite relationship also represents the complexity of symbiotic relationships in general; each symbiont is interacting with its host, its fellow symbionts, and the environment (Kaschuk et al. 2010). There are additional and synergistic effects at work (Scheublin \& van der Heijden 2006). Thus the study of symbiosis can give us hints of the impacts of a symbiont on its host, but we are a long way from a full understanding of the complexities of these symbiotic relationships.

\section{II-E. Global Climate Change}

Global climate change is impacting ecosystems around the world. However, ecosystems such as those in south Florida, which are at or just above sea level and surrounded by water on three sides, are particularly vulnerable (Maschinski et al. 2011). Coastal ecosystems in south Florida have always had to deal with salinity (Ross \& O’Brien 1994). However, those further inland typically experience salinity only after a major event such as a hurricane or a drought. In recent years, soils inland from the coast have seen increased salinization resulting from altered weather patterns as well as salt 
water intrusion in the groundwater. An increase in soil salinity is often coupled with other factors such as increased temperatures or decreased moisture regimes. What impacts soil salinization will have on native flora and fauna is not well known. Animals may be able to adapt by moving between environments, or migrating further inland. Plants, which can only move through pollination and seed dispersal, will need to adapt quickly to changing soil salinity. One way they may be able to do this is through the arbuscular mycorrhizal symbiosis.

Feng et al. (2002) demonstrated that maize plants inoculated with the AM fungus Glomus mosseae were able to tolerate salt stress that non-AM plants were unable to tolerate. Maize plants associated with AMF had higher dry biomass and equal or higher phosphorus content than the non-AM plants. Daei et al. (2009) demonstrated a similar positive effect on wheat yield and growth with AMF under salinity stress. Hammer and Rillig (2011) examined the effect of salinity on AMF glomalin production, and discovered that glomalin production increases under salinity stress, which could actually have evolved to counteract the de-aggregation of soil that occurs under high salinity levels, thus demonstrating that AMF are interacting with the soil as well as their plant hosts. Finally, Latef and Chaoxing (2011) demonstrated that AMF helped tomato plants combat salinity stress, concluding that AMF may be helping plants to alleviate oxidative stress associated with increased salinity. Arbuscular mycorrhizal fungi have also been found on native plants that have adapted to saline soils, and may be playing a critical role in the plants' growth and survival in those conditions (Estrada et al 2012).

Arbuscular mycorrhizal fungi are critical in global climate change discussions because of their contribution to carbon sequestration in the soil. Much of the carbon 
given by the plant host to the fungus in the AM symbiosis is designated towards fungal hyphal growth or spore formation, thus keeping most of the carbon in the soil. Some carbon and nutrients in the AM fungus is stored in expanded hyphal termini called vesicles. These are often located in the plant host cells as well, and serve as another mode of carbon sequestration. While this is a major benefit conferred by AMF, it is also critical to the understanding of the impacts of habitat destruction such as erosion, deforestation, strip mining, industrial agriculture, and habitat conversion. Any disruption to an ecosystem can have a major impact upon the AMF community in the soil - some AMF communities undergo major turnover, others decrease in diversity or vanish (Entry et al. 2002). Community shifts in AMF can have major impacts upon the aboveground communities of plants and animals as well, and it can take a long time for the community to reestablish. Aside from above- and belowground community shifts, such ecosystem disruptions also release a lot of the soil carbon into the atmosphere, reversing the positive effects of the AMF. The amount of carbon sequestration provided by AMF in the soil should be a major consideration in any deforestation, agricultural, or land conversion decisions. Moreover, the carbon sequestration of AMF can be used to help alleviate global warming at a local scale. For instance, if AM symbiosis were promoted in agriculture, the amount of carbon sequestered by AM fungal hyphae would experience a manifold increase per acre.

\section{METHODOLOGY}

In order to investigate the role of AMF on legumes in pine rockland soils, I collected soil from four pine rockland locations; three in south Florida and one in the Florida Keys. These soils were divided into pots in a shade house at Fairchild Tropical 
Botanic Garden's Center for Tropical Plant Conservation. Four different legume species; Cajanus cajan, Chamaecrista fasciculata, Tephrosia angustissima and Abrus

precatorius, were planted into each of the soils. These legumes were used as capture plants, to 'trap' the arbuscular mycorrhizal fungi and rhizobial bacteria out of the soil (Yao et al. 2010). No inoculum was added. After seed germination, a saline solution was added once a week to half of the plants, in order to compare the effects of salinity on AM-legumes in these four different soils. An autoclaved soil was used as a control, into which the same four species of legume were planted for fitness comparison.

\section{III-A. Soil Collection}

Soil was collected using shovels and a pickaxe at all sites. Soil was collected in buckets, which were covered with aluminum foil and stored in a shady area in the garden house at the Center for Tropical Plant Conservation, until the experiment was set up [ca. three months]. The covered buckets retained some moisture and kept most pests out; however, a few months passed between soil collection and experiment set-up during which time some microbes, particularly arbuscular mycorrhizal spores, may have perished. Thus the capture experiment may not have captured full diversity. It has recently been found, however, that AMF spores can persist for some time in the soil - if they germinate and do not find a host quickly, they can actually retract their hypha and go dormant again until a host is detected or environmental conditions change (Denison \& Kiers 2011). It is thus assumed that most AMF associating with the legume hosts in this experiment are a sufficient representation of the diversity from each area. Soil was not sieved or filtered before being used in the experiment. Some large rocks were removed, but many smaller rocks were added to the pots along with the soil - the presence of small 
limestone rocks helped to simulate actual growing conditions in the pine rockland. Likewise, pine rockland seeds may have also persisted in the soil; some of the 'weeds' removed throughout the duration of the experiment very likely originated from the preliminary pine rockland soil collection.

Four pine rockland fragments were sampled for this study; FIU, CTPC, TREC and BPK. Florida International University [FIU] soil was collected from the Nature Preserve on the MMC campus, from the small area of restored pine rockland, where much of the soil community may have been more adapted to the hammock ecosystem of the rest of the preserve. In addition, during restoration new soil was brought in, therefore some of the soil collected from this restored pine rockland may not have been there for very long. The FIU pine rockland is considered a heavily and recently disturbed pine rockland fragment. Center for Tropical Plant Conservation [CTPC] soil was collected from a small patch of pine rockland that is in the process of undergoing a transition to a hammock ecosystem. This can occur when major environmental conditions change, or more likely when the necessary fire regime for pine rocklands does not occur. In the case of the CTPC pine rockland patch, it did not receive any fire regime, and therefore naturally was transitioning to a hammock. There were still some vestiges of pine rockland, but the dominant tree species in the area were hardwood hammock species, thus it is considered a moderately disturbed pine rockland fragment. Tropical Research and Education Center [TREC] soil, from Homestead, FL, was collected in the most undisturbed pine rockland of the four sites. The soil was red clay, had good aggregates, and the trees were old. The TREC site was also the largest of the pine rockland fragments sampled. It was surrounded by avocado groves and patches of agricultural fields. Big 
Pine Key [BPK] soil was collected from a coastal pine rockland. Soil could not be collected from the Big Pine Key National Wildlife Refuge itself, therefore it was collected from an adjacent private property, with permission. There was a high abundance of Chamaecrista fasciculata growing there. Having been collected from a private property adjacent a preserve, BPK was considered a moderately disturbed site.

In each case, soil was not collected from a single patch within each pine rockland, but was collected wherever soil could be found. Soil was collected from multiple sites within each pine rockland location so that disturbance was minimized. These soil collecting sites varied between being under or next to large trees, or being in open empty patches covered by leaf litter. Therefore a diversity of soil was collected from each pine rockland location. None of the pine rocklands sampled experience fire regimes, thus fire was not a factor in my study. Some soil from each of the above locations was mixed and then autoclaved twice in order to sterilize the soil for use as a control. Sterilized pine rockland soil was used so that the soil texture and composition would not be variables in the control.

\section{III-B. Experimental Design}

The experiment was conducted in a shade house at the Center for Tropical Plant Conservation, a research area for Fairchild Tropical Botanic Garden. The location exposed the plants to the elements, which made a regimented watering treatment more difficult, yet maintained the more 'natural' weather variation that south Florida pine rockland plants and soil would have experienced. The experiment was set up on tables to attempt to minimize pests and potential flooding during rains. Soil was added to conetainers of three sizes; large $\left(163.8 \mathrm{~cm}^{3}\right)$, medium $\left(106.5 \mathrm{~cm}^{3}\right)$, and small $\left(49 \mathrm{~cm}^{3}\right)$. 
Conetainers are specialized cone-shaped planting pots, which maximize the potential root surface area for interaction with the soil. They also allow for easy harvest. The conetainers were set in trays elevating them above table height. Unfortunately the smallest sized conetainers were not elevated to the same height as the medium and large conetainers, thus they may have experienced some shading and different microclimates. Three different conetainer sizes were used in order to maximize capture of the microbial symbionts from the soil. The idea behind this is that rarer or less competitive species could be given an opportunity to get to the roots of the plant host first in a smaller space, which in uniformly large pot sizes would not have a chance to get to the host plant (Audet \& Charest 2010, Janos 2011). Four host plants were chosen, and seeds of each host plant were placed into each of the four soil types [plus the sterile control], in each of the three different pot sizes. A saline solution was added to half the samples, and each treatment had three replicates. Two tables were set up; one which had an early, preflowering harvest, and one that had a later, post-flowering harvest. As plants mature, some take on different communities of microbial symbionts at different parts of their life cycles, such as during flowering time (Janos 2011). By using two different harvest times, I accounted for this potential AMF community shift. With all treatments, the experiment had a total of 720 conetainers, each with one host plant type in one soil type with either saline or nonsaline treatment. Excluding harvest time, table 1 and table 2 were identical, and each contained 360 conetainers.

The four host plants chosen for this shade house experiment are Cajanus cajan, Chcamaecrista fasciculata, Tephrosia angustissima, and Abrus precatorius. Cajanus cajan, or pigeonpea, is a crop legume. It is grown occasionally in south Florida, but is a 
much more important crop in other parts of the world. Pigeonpea is a dominant crop in many parts of Asia, where its annual production is 3.8 million tons. It is also an important crop in parts of Africa, and to a lesser extent in Latin America and the Caribbean (Varshney et al. 2011). It is a very important crop because it is a good source of protein, and is vital in areas where other sources of protein are limiting. An understanding of the effect of the AM symbiosis on pigeonpea could have important impacts on the production of pigeonpea crops in the future. Chamaecrista fasciculata is the dominant Chamaecrista species in south Florida and can be found throughout the eastern United States. It has two sister species that are rare or endangered in pine rockland areas and similar habitats. A better understanding of the effects of the AM symbiosis on this native legume could impact restoration and conservation decisions, and could become a component of a larger biogeographical study of this species throughout its native range. Tephrosia angustissima is a threatened legume species in south Florida pine rocklands. If the AM symbiosis is shown to have positive effects on this legume, native AMF inocula could be used in conservation and replanting initiatives. Finally, Abrus precatorius, also known as crab's eye vetch or rosary pea, is an invasive exotic legume in south Florida pine rocklands. If native AMF have a positive effect on the growth of rosary pea, this could have dramatic impacts upon our understanding of invasive biology as well as how to deal with invasive exotic plant species.

Research assistants used plastic gloves to fill each conetainer with pine rockland soil [either FIU (soil 1), CTPC (soil 2), BPK (soil 3), TREC (soil 4) or Sterile Control (soil 5)] to within $3-5 \mathrm{~cm}$ of the top of the conetainer. Each person was assigned to a specific soil type so that no cross-contamination took place. Over time, some soil had to 
be added to the conetainers as a result of soil compaction or erosion. Particularly after the heavy rains experienced during the first two weeks after planting, a good deal of soil was lost. Once soil was added to each conetainer and the conetainers were arranged by soil type on the tables, one legume seed [either C. cajan, C. fasciculata, T. angustissima, or A. precatorius] was planted $2-4 \mathrm{~cm}$ deep into the soil and covered. Each week after planting, seeds were monitored for growth. Once growth appeared, seedling height was measured. After three weeks of growth, an N/P limited Hoaglands solution [Limited Hoagland's solution: diluted amounts of calcium, potassium, iron, magnesium sulfate, manganese chloride, copper sulfate and zinc sulfate in $1 \mathrm{~L}$ DI water] was added to the plants. One $\mathrm{mL}$ of N/P limited Hoaglands was added to each conetainer, dispersed around the base of the seedling. Care was taken not to apply the Hoaglands directly on the seedling. Also after three weeks of growth, a 10ppm saline solution was added to those plants receiving saline treatment. Again, $1 \mathrm{~mL}$ of $10 \mathrm{ppm}$ saline solution was added to each conetainer in the saline treatment, around the base of the seedling. Hoaglands and saline solution were never applied at the same time.

Besides being exposed to the rain, during dry times the plants also received watering from the shade house sprinkler system. Four weeks after planting, heavy herbivory, from snails and other pests, was observed on the seedlings. A minimal amount of "Snail Bait" was added only to those plants observed to experience herbivory, and any herbivores observed were manually removed. Following the first harvest, which comprised the plants on table 1, ants were observed in some of the conetainers on table 2 , mainly in the CTPC soil, and actually appeared to be defending their respective plants. 
Thus the experimental design experienced additional variables that may have had an impact on the symbiotic relationship of the legume hosts and their AMF communities.

\section{III-C. Monitoring and Harvest}

As plants grew, their height was measured on a weekly basis. Height (in centimeters) was measured by placing a ruler at soil level and measuring to the 'top' (the highest point, whether stem tip or leaves) of the plant. Conetainers were monitored for pests and weeds, and any pests or weeds observed were manually removed. This experiment took place from May to August of 2012, with average temperatures around $27 * \mathrm{C}$ and frequent rain and thunderstorms. Following the harvest of table 1 , yet preceding the harvest of table 2 , all conetainers from table 2 had to be brought inside for a 48-hour period during a tropical storm. They were then brought back outside to the shade house for a few weeks before the second harvest.

After eight weeks of growth, plants on both tables were sizeable and leafy, but had not yet begun flowering. This was the time chosen to harvest plants from table 1 . Following twelve weeks of growth, with observed flowers and even some pods on plants

on table 2, the second harvest was scheduled. Each harvest consisted of all components of the plant from each conetainer being collected for analysis. Each rack of conetainers was brought via a cart from the shade house to a washing station next to the garden house at the Center for Tropical Plant Conservation. Conetainers were gently squeezed to loosen the contents, then emptied onto a plastic tray. Three leaves were collected from each plant for nutrient analysis. The shoot was then cut from the roots, and placed in a paper bag to be dried and weighed. Soil was collected in a $5 \mathrm{~mL}$ soil collecting bag [Whirlpak] for further analysis. Roots were then carefully washed using a hose with low water 
pressure, and the entire root, along with any stray nodules and root tips, were placed in a Ziploc plastic bag for subsequent processing. All bags were labeled in advance. Each conetainer was then thoroughly washed with the hose, then placed to the side to dry. Excess soil was added, with permission, to the CTPC compost for reuse.

Following harvest, all collections were stored at room temperature in the lab, except for the roots which were stored in a $4 * \mathrm{C}$ refrigerator in the lab. Bags of roots were removed, ten at a time, from the refrigerator; nodules were counted and removed, and root tips were removed. $1-3 \mathrm{~cm}$ was collected from the ends of the root to serve as root tips. Root tips were wrapped in thin wedding veil, and placed in small plastic cassettes. These would be used for percent colonization analysis (Vierheilig et al. 2005).

\section{III-D. Plant Fitness Measures}

In order to investigate the impact of arbuscular mycorrhizal fungi on their plant hosts, three measurements were used as proxies for plant fitness values. These included growth rate, shoot biomass and root biomass.

Growth rate was measured as the average change in plant height in $\mathrm{cm} /$ week. For table 1, growth rate covers an eight week period, and for table 2, growth rate covers a twelve week period. Plant height was measured using a ruler placed at soil level, and measuring to the 'top' of the plant. Occasionally change in height was negative because

of branching, dieback, change in soil level through compaction or erosion, or the plant growing so tall that it began to lean over. Therefore, while change in plant height over time serves as a proxy for fitness, it alone is not an ideal measure. Some of the growth begins slowly, then shoots up in the last few weeks - this may be a result of plant growth patterns or may be because of the fact that the first few weeks after seeds were planted 
experienced heavy rains, followed by more sunshine interspersed with some rain. An initial saturation may have impacted the initial growth of the seedlings, and may even have impacted the initial symbiotic associations of the seedlings.

Once nodules and root tips were removed for analysis, roots were then placed into labeled paper bags. Roots were allowed to dry at room temperature for 48 hours, then placed in a large drying oven at $80^{\circ} \mathrm{C}$ for three days. They were then removed and weighed on an electronic balance, and root dry weights were recorded. Shoots, which had been stored at room temperature in the lab, were also placed in the large drying oven at $80^{\circ} \mathrm{C}$ for two days. They were then removed and weighed on an electronic balance, and shoot dry weights were recorded.

\section{III-E. Percent Colonization}

Root tips in cassettes were placed in $10 \%$ potassium hydroxide $(\mathrm{KOH})$ solution, and digested at room temperature for twenty-four hours. Chamaecrista fasciculata roots, which were highly pigmented, were digested in $20 \% \mathrm{KOH}$ solution. Cassettes were removed from the $\mathrm{KOH}$ solution, washed three times with deionized (DI) water, and then soaked in hydrogen peroxide for five minutes. Cassettes were washed again three times with $\mathrm{DI}$ water, and then soaked in $1 \%$ hydrochloric acid $(\mathrm{HCl})$ for five minutes. $\mathrm{HCl}$ was poured off, and cassettes were immediately transferred to a container of Trypan Blue Solution [Trypan Blue Solution prepared with $800 \mathrm{~mL}$ glycerin, $800 \mathrm{~mL}$ lactic acid, $800 \mathrm{~mL}$ distilled water and $1.2 \mathrm{~g}$ trypan blue dye], and allowed to soak for twenty-four hours. Cassettes were then removed from the Trypan Blue Solution, and washed three times with DI water. They were stored in the $4^{\circ} \mathrm{C}$ freezer for further analysis, up to a period of three weeks. Cassettes were removed from the freezer, allowed to thaw, then 
stained root tips were placed along with some DI water on a glass slide and covered with a glass cover slip. They were analyzed on a compound microscope at 100x. Root tips were examined for the presence of vesicles [Fig. 2], arbuscules [Fig. 3], and hyphae. AMF hyphae are distinguished from other fungal hyphae on roots by the lack of septa. The presence of AMF propagules [Fig. 4] or spores was also noted, but was not used in analysis. Percent colonization was calculated by counting the number of root tips in a sample colonized by AMF [presence of vesicles, arbuscules and/or hyphae] divided by the total number of root tips in the sample. My protocol follows that of Dr. Abid Al Agely at the University of Florida.

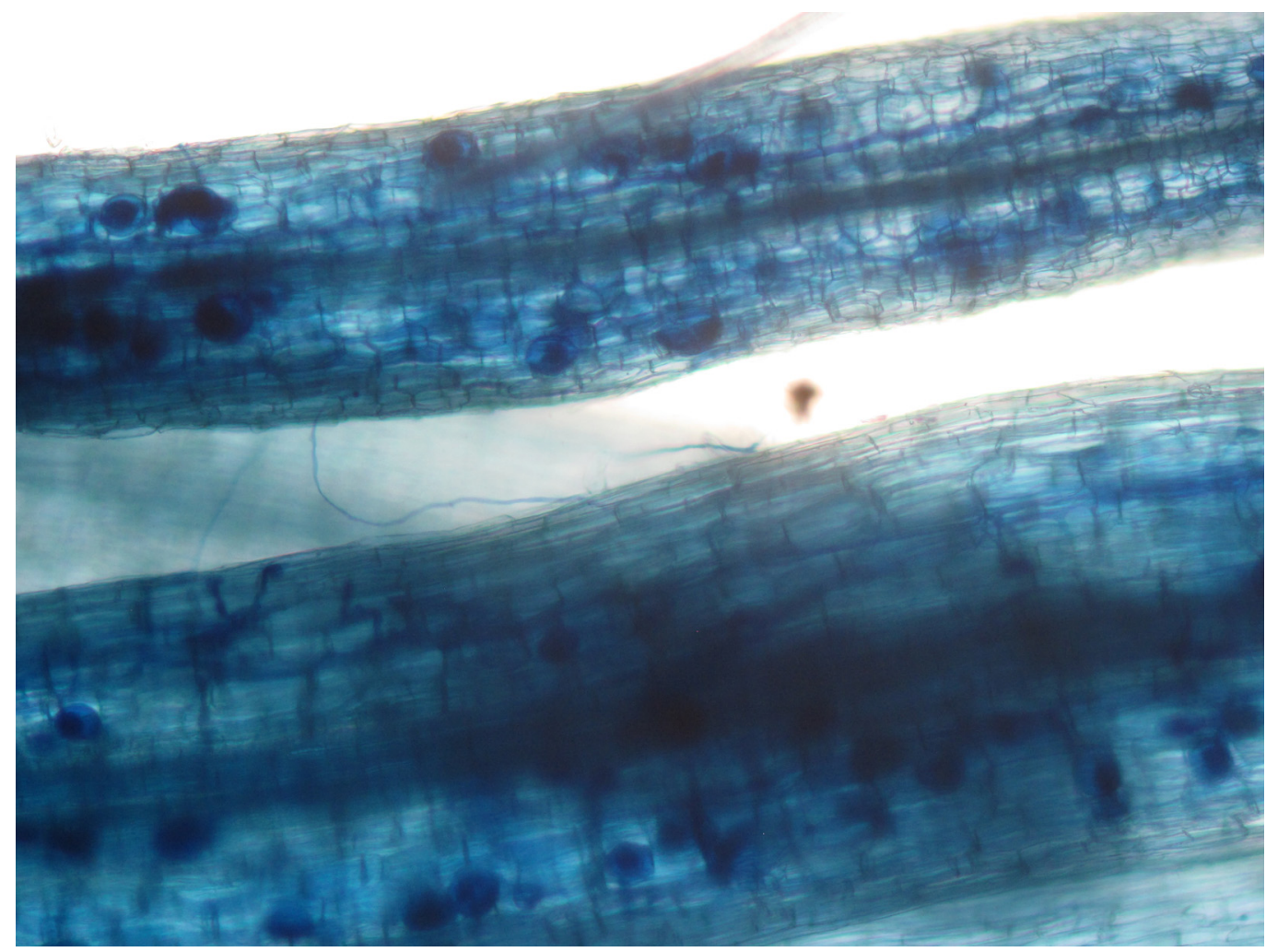

Figure 2. Image of vesicles inside a root taken using $10 \mathrm{X}$ compound lens 


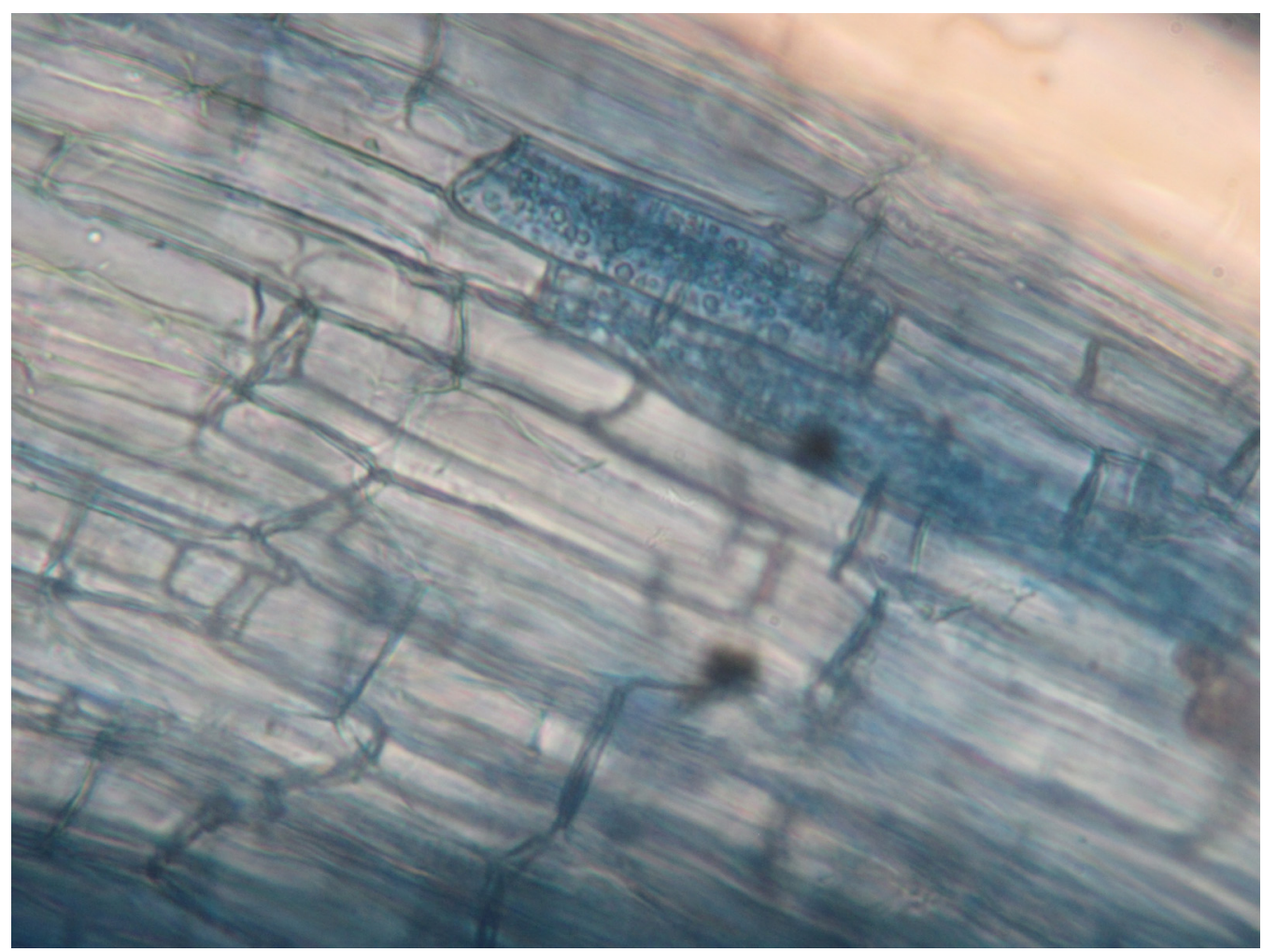

Figure 3. Image of arbuscules inside a root taken using 40X compound lens

\section{III-F. Spore Identification}

Soil samples from each soil type [FIU, CTPC, BPK and TREC] were analyzed for spore diversity. Collections were only made from non-saline treated soil for this assessment. One gram of wet soil was weighed on the electronic balance, then placed in a small mixer with $25 \mathrm{~mL}$ of DI water, and blended. The blended soil mixture was then poured over three sieves of decreasing pore size $(2 \mathrm{~mm}, 850 \mu \mathrm{m}, 45 \mu \mathrm{m})$. Each level of the sieves was washed with DI water until it seemed like all possible material had passed through, until the final sieve, whose contents [mainly silt and spores] were washed into a $15 \mathrm{~mL}$ polypropylene tube. The tube was topped off with DI water, vortexed, and stored in the refrigerator. Using a disposable pipette, the spore solution was dropped onto a piece of filter paper on a glass slide, which was placed on the stage of a compound 
microscope, and spores were observed at 100x. Spores were counted using a counter. Each novel spore encountered was described, and assigned a "species number." Spores were identified to genus level using INVAM, the International Culture Collection of VA Mycorrhizal Fungi, and analyzed based upon genus and spore morphology. Color was described as brown, translucent or white. Size was described as small, medium or large. Texture was described as indented, oval, capped, ornamented, round or cube. Some spores had more than one of these texture properties, so the distinguishing property [eg. for generic identification] was chosen for the description. See Fig. 4 for examples of spore morphologies.

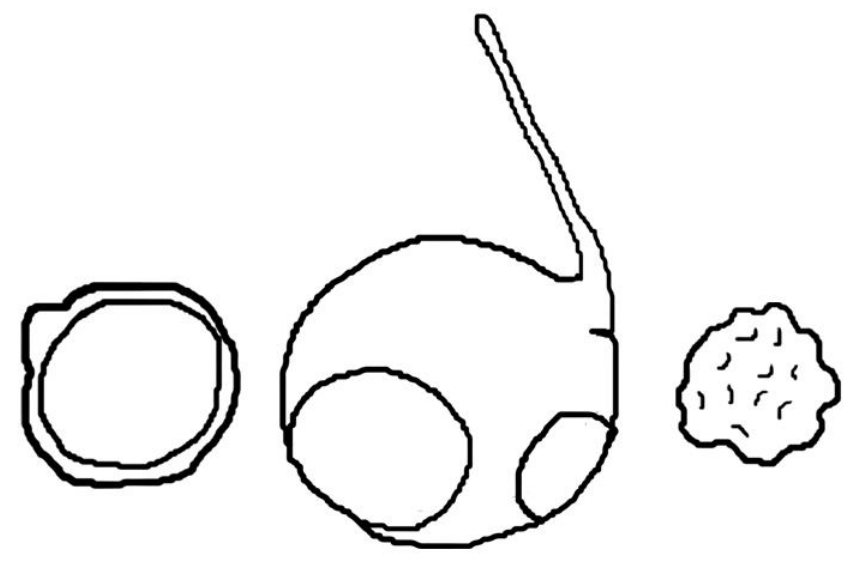

Figure 4. Diagram of different spore morphologies. From left to right, medium round, large capped, and small indented.

\section{III-G. Nutrient Content}

Before setting up the shade house experiment, soil samples were gathered from each of the four soil types [FIU, CTPC, BPK and TREC] in 5mL Whirlpak soil collection bags, and brought to the A\&L Southern Agricultural Laboratories, LLC for soil nutrient analysis. Soil nutrient content (phosphorus, magnesium, calcium, sodium and nitrate) was assessed by A\&L Agricultural Laboratories [Fig. 5]. 
Leaf samples were dried in a $60^{\circ} \mathrm{C}$ oven and ground using a Qiagen Tissue Lyser with tungsten beads. Leaf samples from each treatment were separated out for micronutrient and phosphorus content using an Inductively-Coupled Plasma Optical Emission Spectrometer at the United States Department of Agriculture south Florida branch. Once dried and ground, samples were placed in polypropylene tubes, where $250 \mu \mathrm{L}$ of $70 \%$ nitric acid was added to each sample, vortexed, and allowed to soak for three hours. They were then placed in a dry heating block at $90^{\circ} \mathrm{C}$ for eight hours. Samples were then removed, and allowed to cool to room temperature. Fifty $\mu \mathrm{L}$ of $30 \%$ hydrogen peroxide was added to each sample, then placed in the dry heat block at $90^{\circ} \mathrm{C}$ for thirty minutes. Samples were removed and allowed to cool, then $50 \mu \mathrm{L}$ of $30 \%$ hydrogen peroxide was added again and the samples were heated at $90^{\circ} \mathrm{C}$ for another thirty minutes. Samples were removed, allowed to cool, then diluted with DI water to a final volume of $10 \mathrm{~mL}$ and vortexed. One $\mathrm{mL}$ of this solution was added to $9 \mathrm{~mL}$ of $0.8 \mathrm{M}$ nitric acid for a final volume of $10 \mathrm{~mL}$ and vortexed. Samples were stored temporarily in the refrigerator, then delivered to the United States Department of Agriculture (USDA) research facility on Old Cutler Road for ICP-OES analysis.

Leaf samples from each treatment were also prepared for nitrogen and carbon content analysis using a Carbon-Nitrogen Elemental Analyzer at Florida International University. Leaf samples were dried and ground, as above, weighed, and placed in small pieces of aluminum foil, wrapped up, and placed in the analyzer. Occasionally leaf weights were too low and got misread by the machine. Those measurements were discarded. 


\section{III-H. Statistical Analysis}

All analyses were performed in SAS 9.3 (SAS Institute, Cary, NC, USA). Differences in plant growth traits (growth rate, root and shoot dry weight), root colonization traits (percent colonization), and nutrient levels across treatments were assessed with multivariate analysis of variance in PROC GLM. Analyses were performed separately for each plant species. I assessed the effects of soil, pot size, and salinity treatment. Interaction terms were included, but three way interactions were excluded as none were significant $(\mathrm{P}>0.2)$. I used type III sum of squares, and treated all three factors as fixed effects. Posthoc comparisons were made with least square means comparisons.

\section{III-I. Limitations of Study}

My study demonstrates the effects of arbuscular mycorrhizal fungi on their legume plant hosts in pine rockland soils under normal and saline conditions. Percent colonization is used as a measure of overall symbiotic activity. Since it cannot distinguish among individual fungi, it cannot be used to demonstrate an increase or decrease in individuals infecting the root, nor an increase or decrease of an individual AM fungus' activity. I was able to measure the overall symbiotic activity between legume hosts and AM fungi under various conditions, but to be able to distinguish between increased association of individual AM symbioses or increased number of AMF symbionts per host plant would require further investigation.

Though three replicates were made for each cross of soil-plant-conetainer sizesalinity, due to heavy rains and other factors, some seeds did not germinate and some plants died in the duration of the experiment, reducing the number of replicates and in 
some cases preventing thorough statistical analysis. Should the experiment be replicated in the future, it is recommended to do it inside a more controlled, greenhouse setting, and to perhaps also avoid south Florida summer as seed-planting time.

Syrkorová et al. (2007) demonstrated that greenhouse trap experiments are subject to a cultivation bias, and do not capture the full diversity from the field. They furthermore showed that even capture plants transplanted to the field hosted a different community of AMF than native plants growing in the field. Therefore I acknowledge that the use of four legume trap plants in my experiment will not fully capture the diversity of AMF from each of the pine rockland locations, and may not even fully represent the AMF communities that would associate with these same legume species growing in the field. My experiment can nevertheless provide some insight into the impacts that these AM associations have on these legume species in these soil types, which provides a baseline for future research in the field.

Spore morphology has long been used to identify AMF species. However, with recent advances in molecular tools for AMF identification, it has been discovered that morphological identification is not sufficient (Krüger et al. 2009). Some species of AMF can form multiple kinds of spores, which formerly were placed into different orders, while other species with very similar looking spores, all lumped into one genus, Glomus, have now been found to be genetically distinct. The use of spore morphology is just the first step in assessing diversity; a more in-depth diversity and community composition assessment would require the use of molecular tools. 


\section{RESULTS}

\section{IV-A. Soil Nutrients, Plant Fitness Traits and Percent Colonization}

Soil was analyzed for nutrient content, and plants were analyzed for growth rate, shoot biomass, root biomass and percent colonization by AMF per soil type, pot size, and salinity treatment. The first harvest [table 1] and the second harvest [table 2] were analyzed separately.

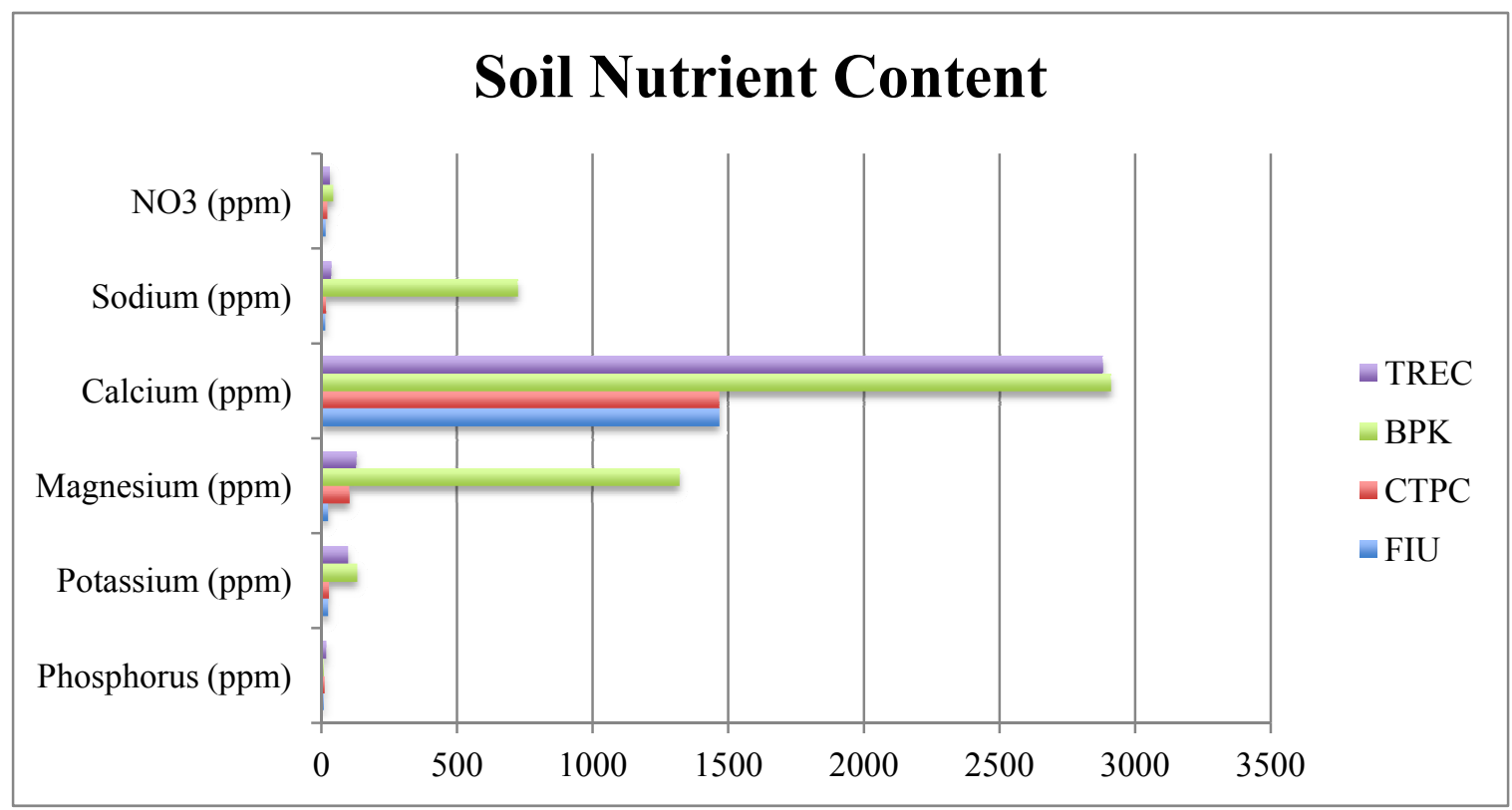

Figure 5. Soil nutrient composition of four pine rockland locations, in ppm.

All sites had high levels of calcium (above 1400ppm), yet this is to be expected since pine rocklands are comprised of calcium carbonate. The TREC and BPK sites had the highest calcium levels. Big Pine Key had the highest magnesium and sodium levels (1318ppm and 2908ppm, respectively) - this too is to be expected as it was a pine rockland right on the coast of an island, with direct exposure to sea water. All of the sites had very low levels of phosphorus, with TREC having the highest amount of $16.6 \mathrm{ppm}$. It is expected that associations with AMF will help plants to get to this limiting nutrient. 


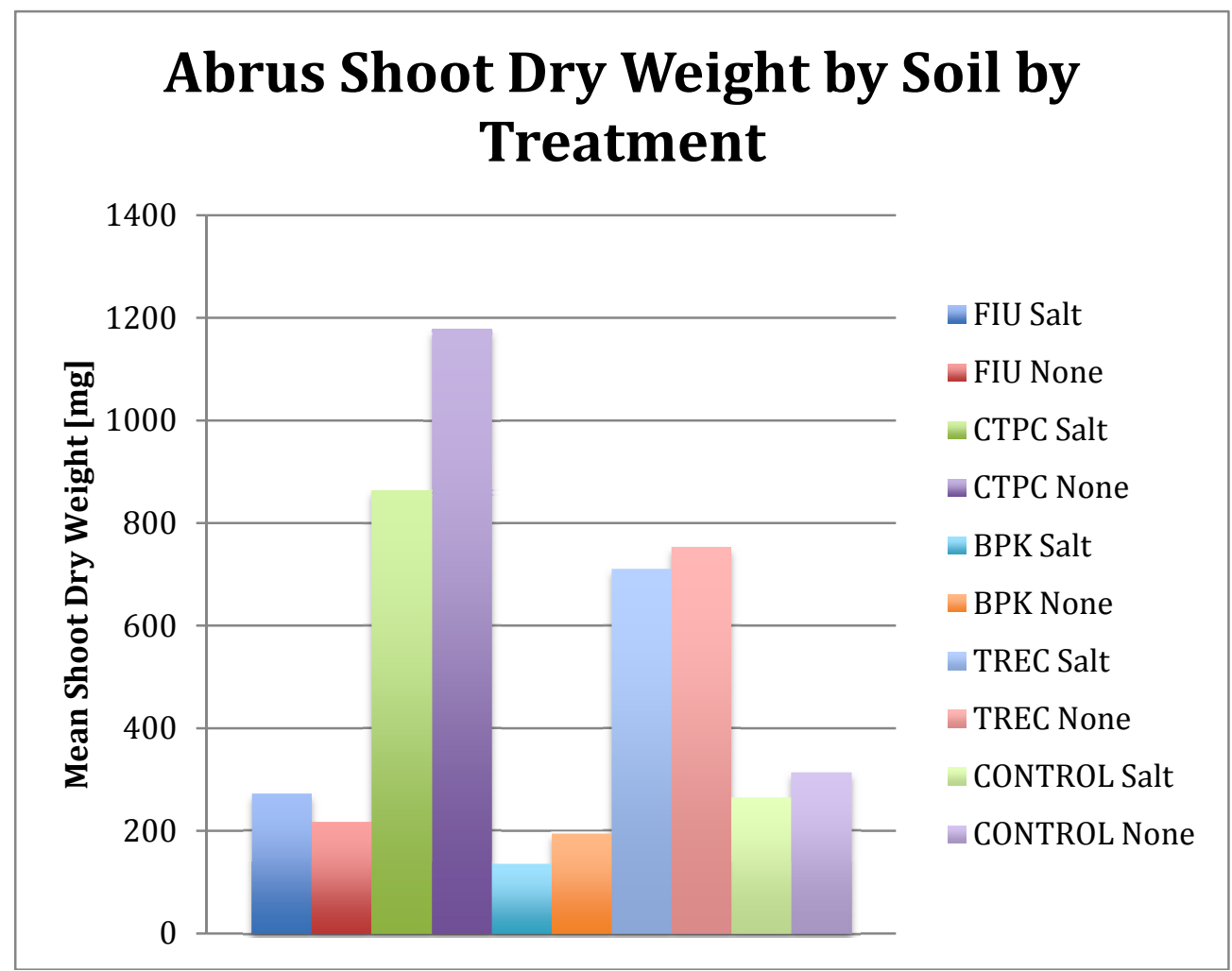

Figure 6i.

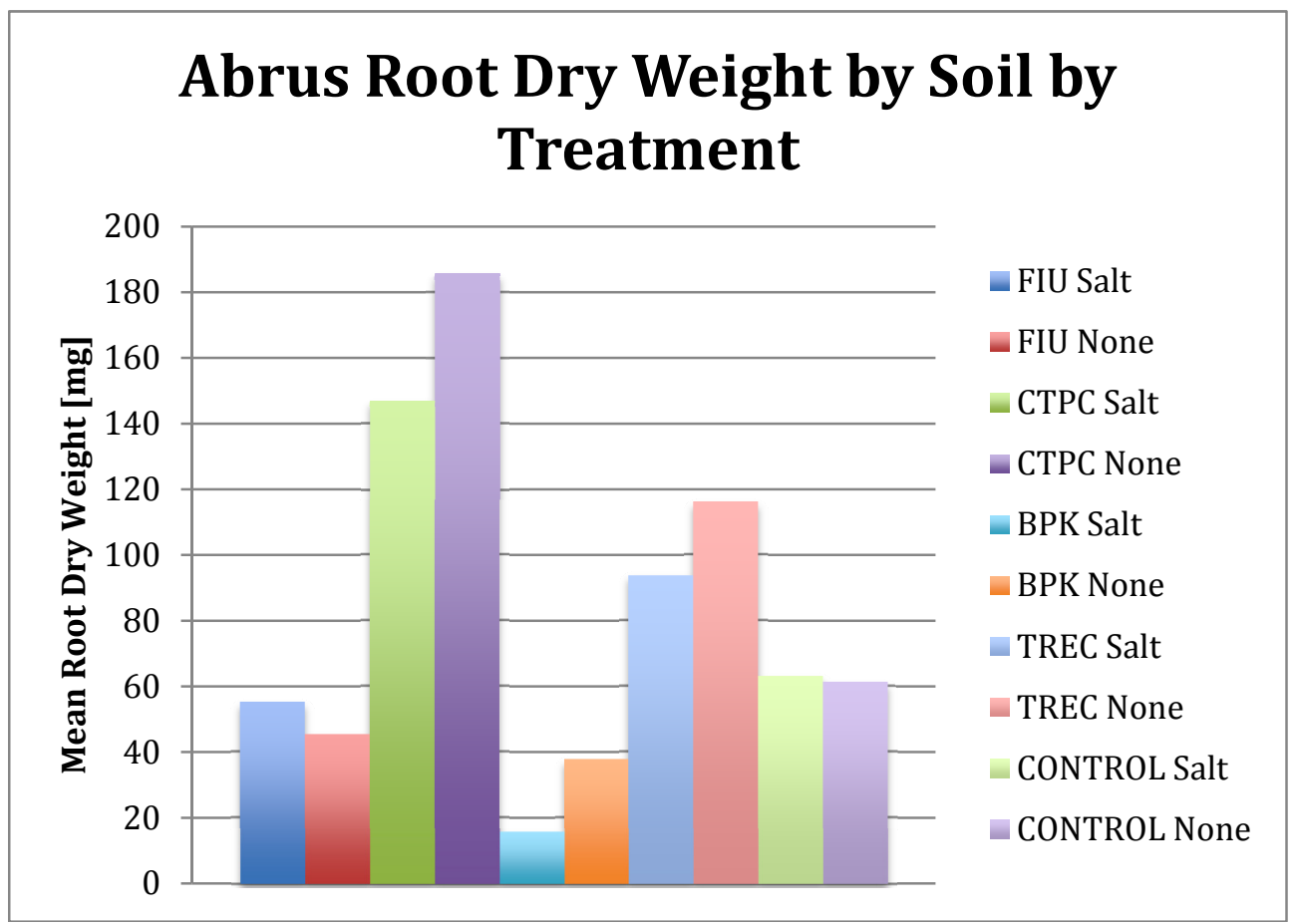

Figure 6ii. 


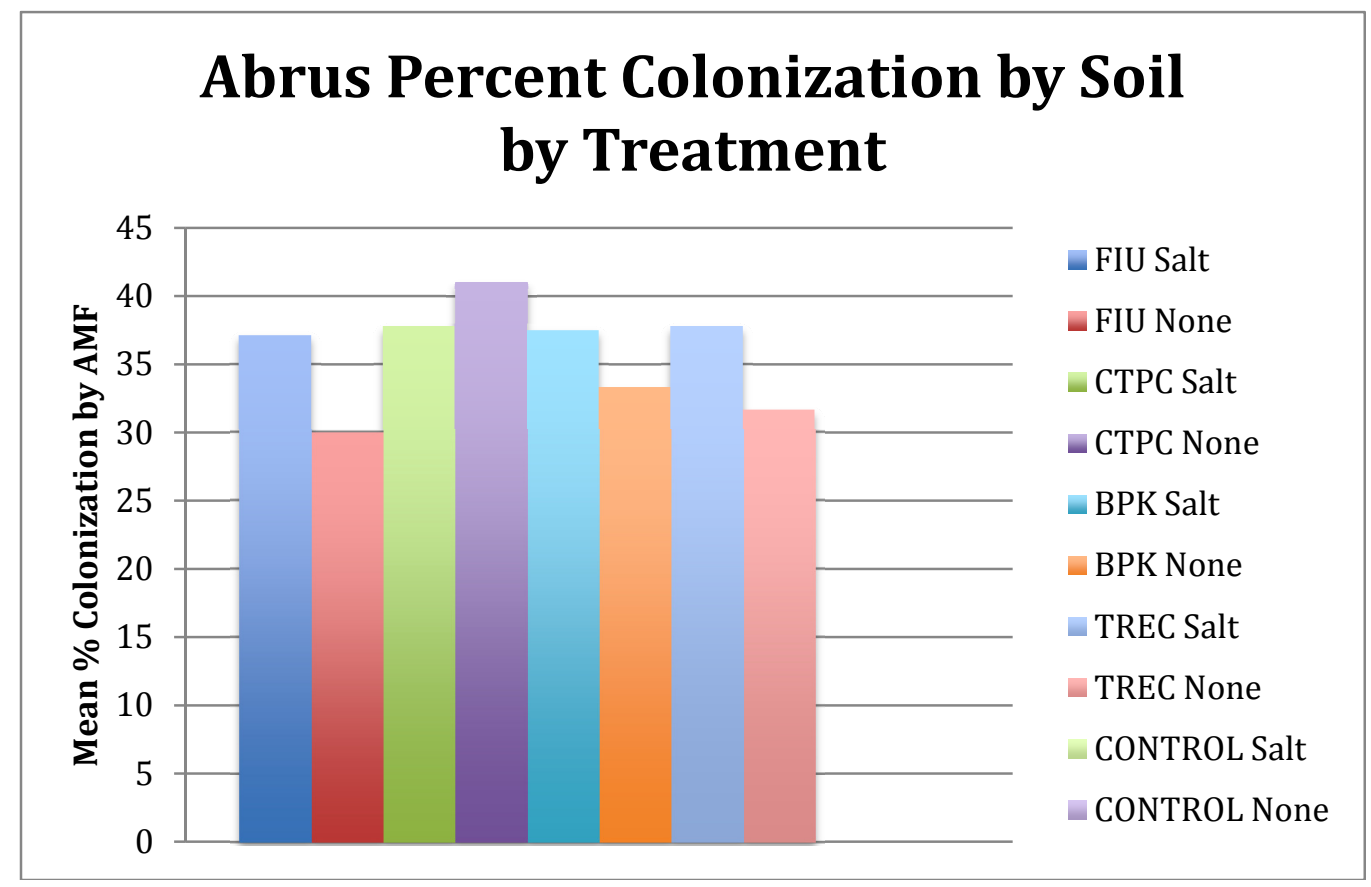

Figure 6iii.

On table 2 [second harvest], Abrus precatorius had a mean shoot dry weight higher in the non-salt treatment than the salt treatment for all soils [CTPC, BPK, TREC and CONTROL] except FIU. Mean shoot dry weights were highest in CTPC soil and lowest in BPK soil. Root dry weights followed the same trend as shoot dry weights, except that mean root dry weight in the salt treatment in the sterile CONTROL soil was slightly higher than non-salt mean root dry weight. Mean root dry weights, like shoot dry weights, were highest in CTPC soil and lowest in BPK soil. Percent colonization did not vary extensively between the different soils and treatments; in FIU, BPK and TREC, mean percent colonization was higher in the salt treatment than the non-salt treatment, however, in CTPC soil mean percent colonization was lower in the salt treatment than the non-salt treatment. The sterile CONTROL soil, as expected, did not have any percent colonization of AMF in the roots. 


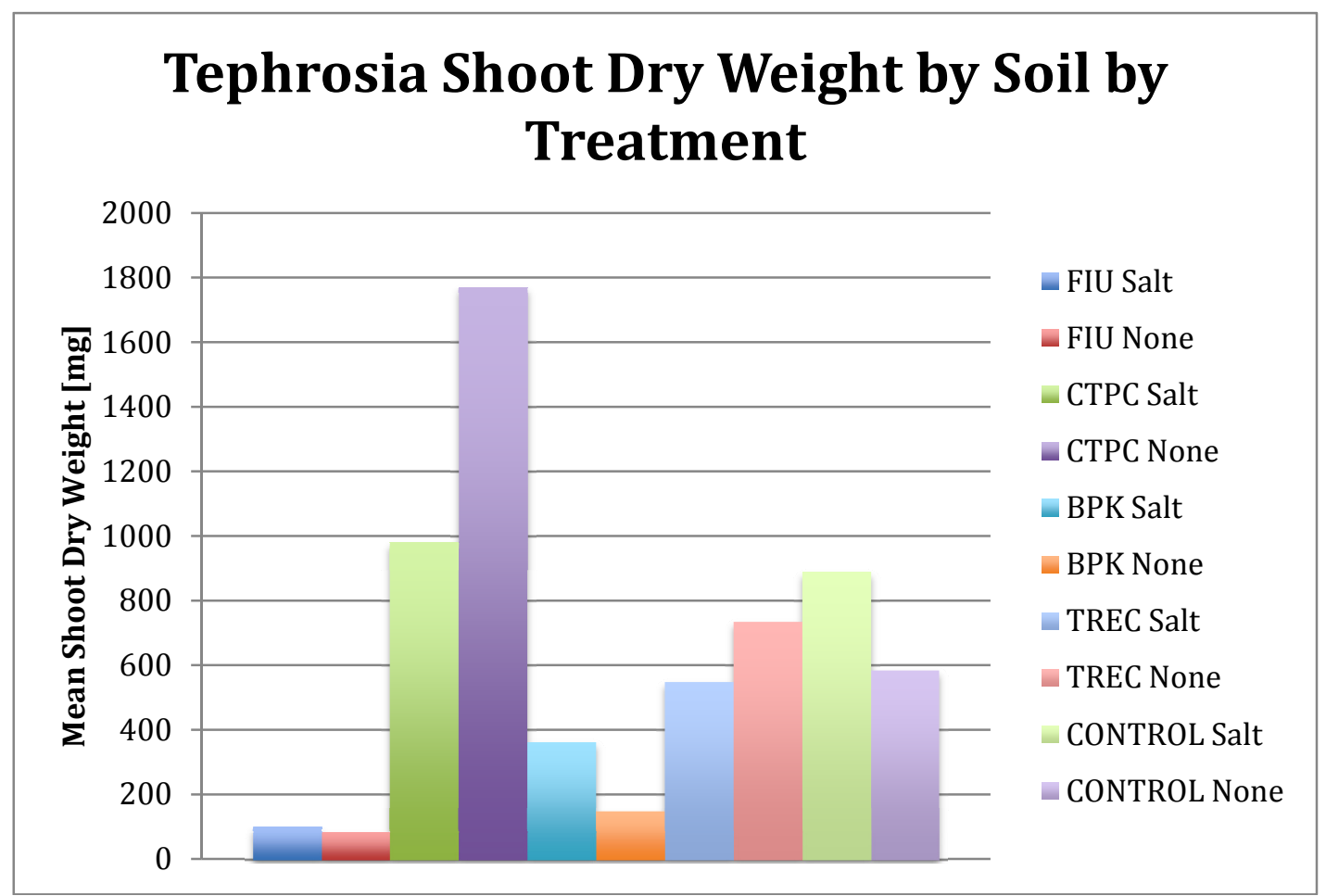

Figure 6iv.

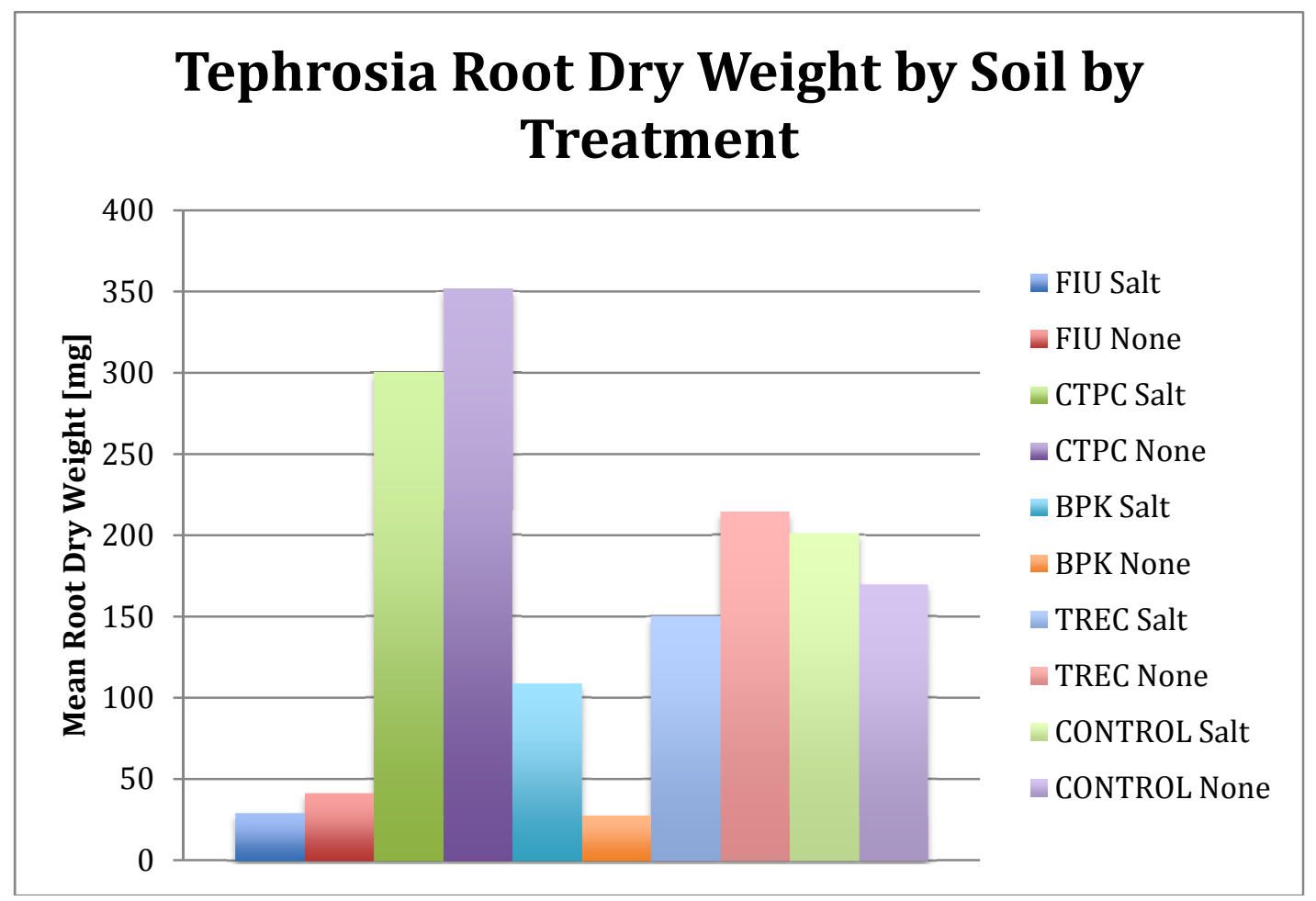

Figure 6v. 


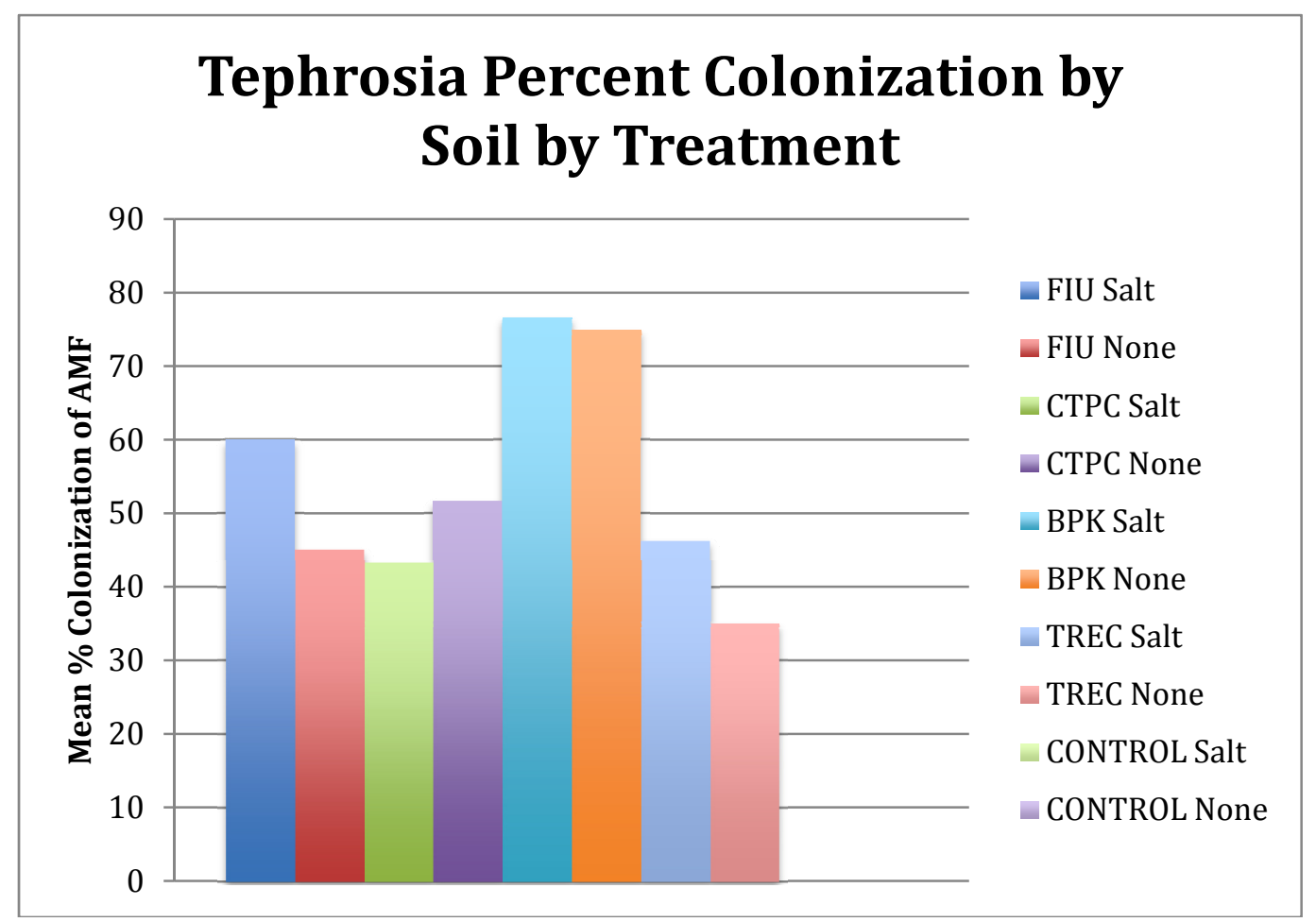

Figure 6vi.

On table 2 [second harvest], Tephrosia angustissima varied quite a bit in terms of fitness proxies shoot dry weight and root dry weight between the different soil types and salinity treatments. Both shoot and root mean dry weights were highest in CTPC soil. In CTPC and TREC soils, both shoot and root mean dry weights were higher in the non-salt treatment than the salinity treatment. The BPK and CONTROL soil treatments saw lower mean shoot and root dry weights in the non-salt treatment than the salinity treatment. Florida International University soil had higher mean shoot dry weight in the salinity treatment, and lower mean root dry weight in the salinity treatment. In FIU, BPK and TREC soils, percent colonization was lower in the non-salt treatment, but in CTPC soil, percent colonization was lower in the salt treatment. 


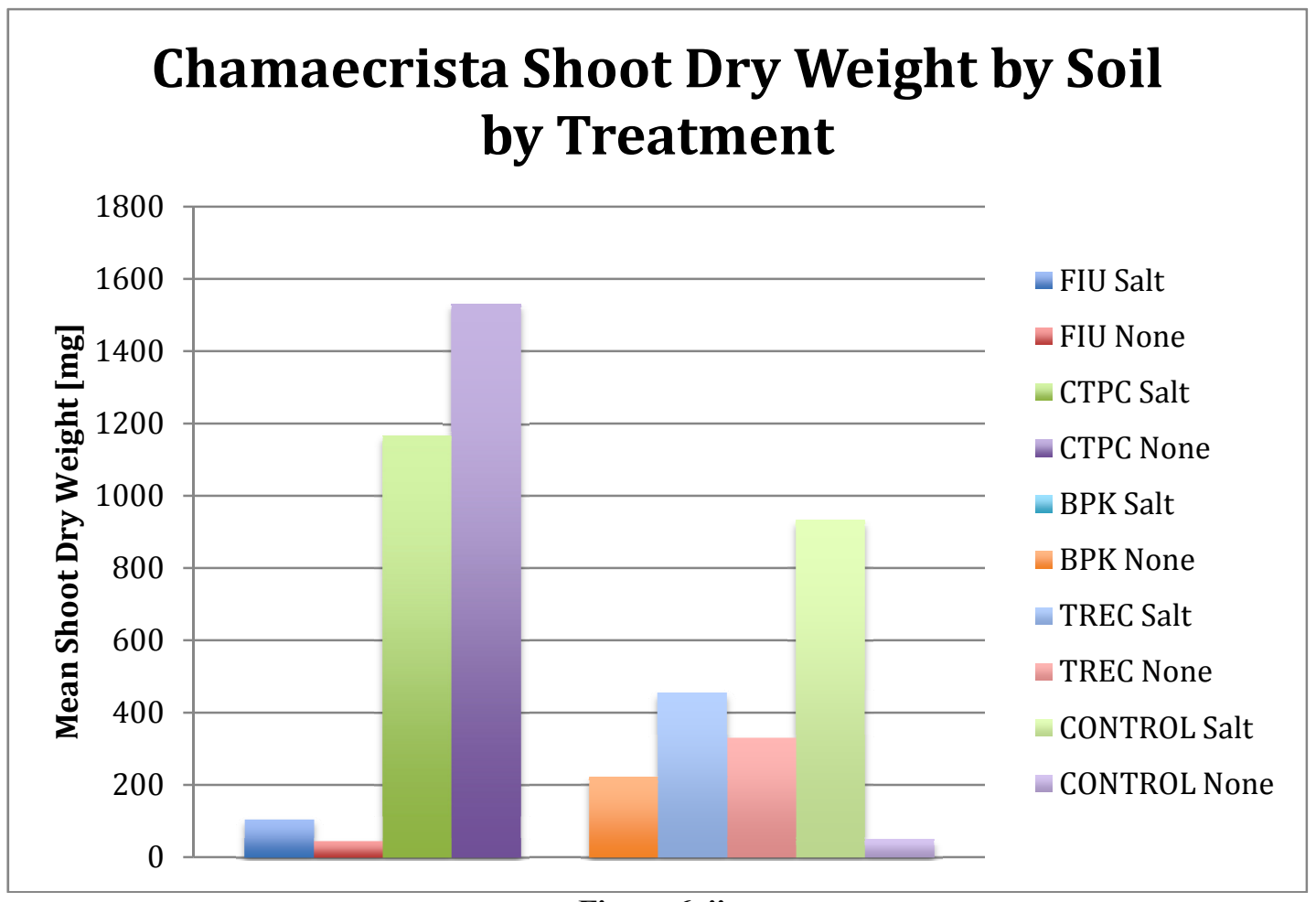

Figure 6vii.

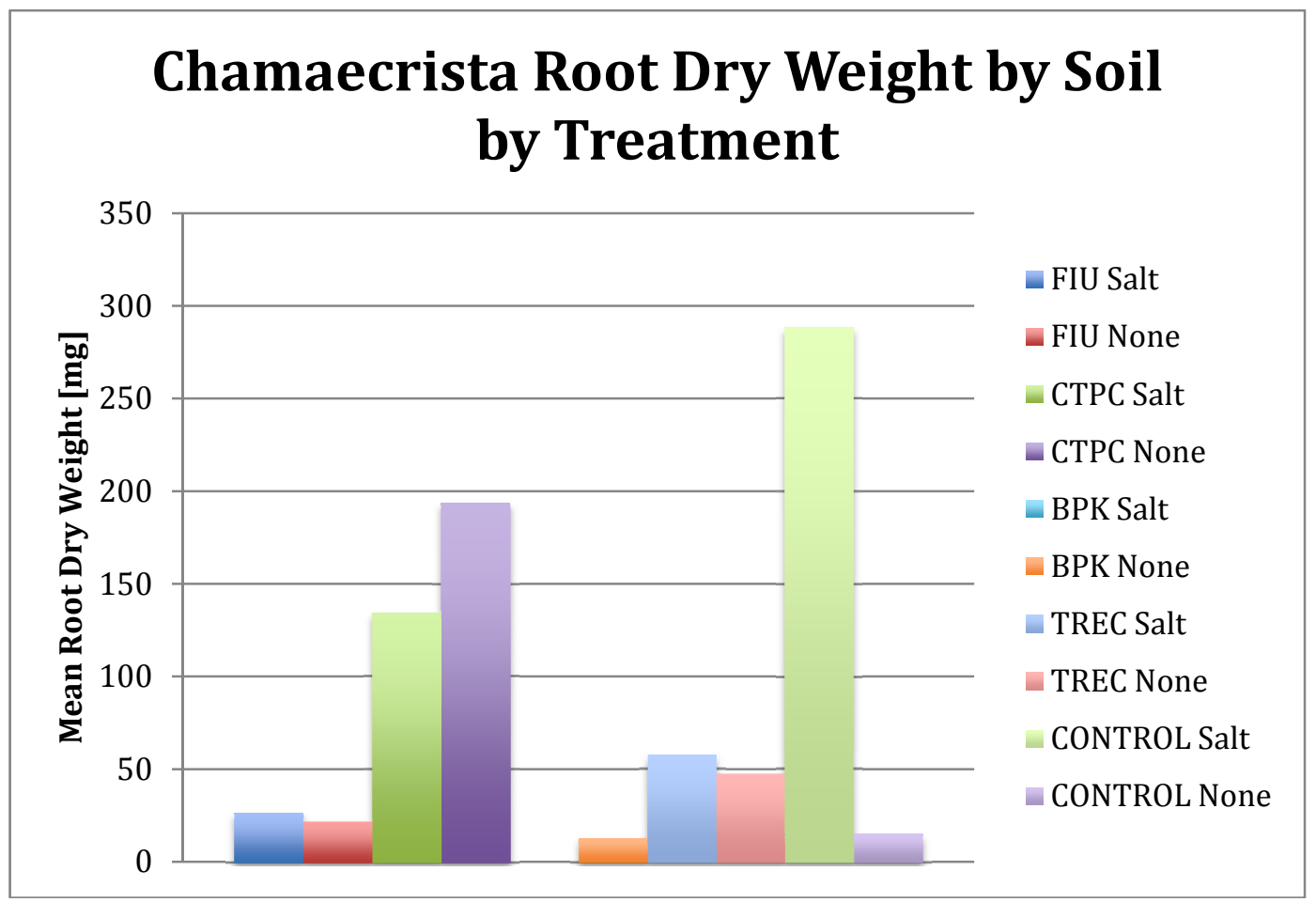

Figure 6viii. 


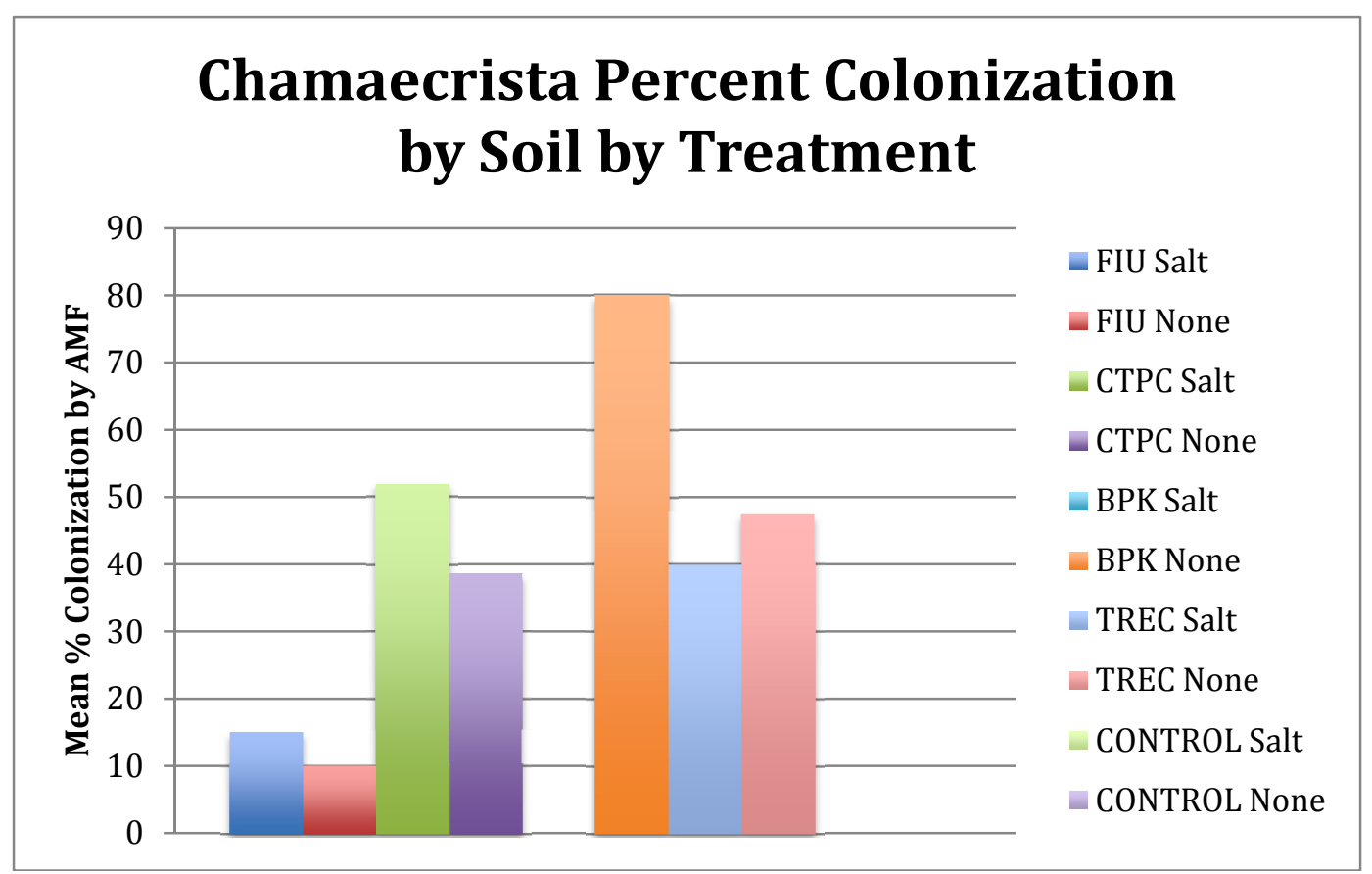

Figure 6ix.

On table 2 [second harvest], Chamaecrista fasciculata had the highest mean shoot dry weight in CTPC soil non-salt treatment, and the highest mean root dry weight in the CONTROL soil salt treatment. Chamaecrista fasciculata had the lowest mean root and shoot biomass [0] in BPK soil saline treatment because no plants germinated in that treatment. Soils FIU, TREC and CONTROL had higher mean shoot and root dry weights in the salt treatment than in the non-salt treatment, while CTPC and BPK had lower mean shoot and root dry weights in the salt treatment. Percent colonization by AMF was higher in the salt treatments in FIU and CTPC soils, but lower in the salt treatment in TREC soil. BPK cannot be considered, as not plants germinated in the salt treatment. 


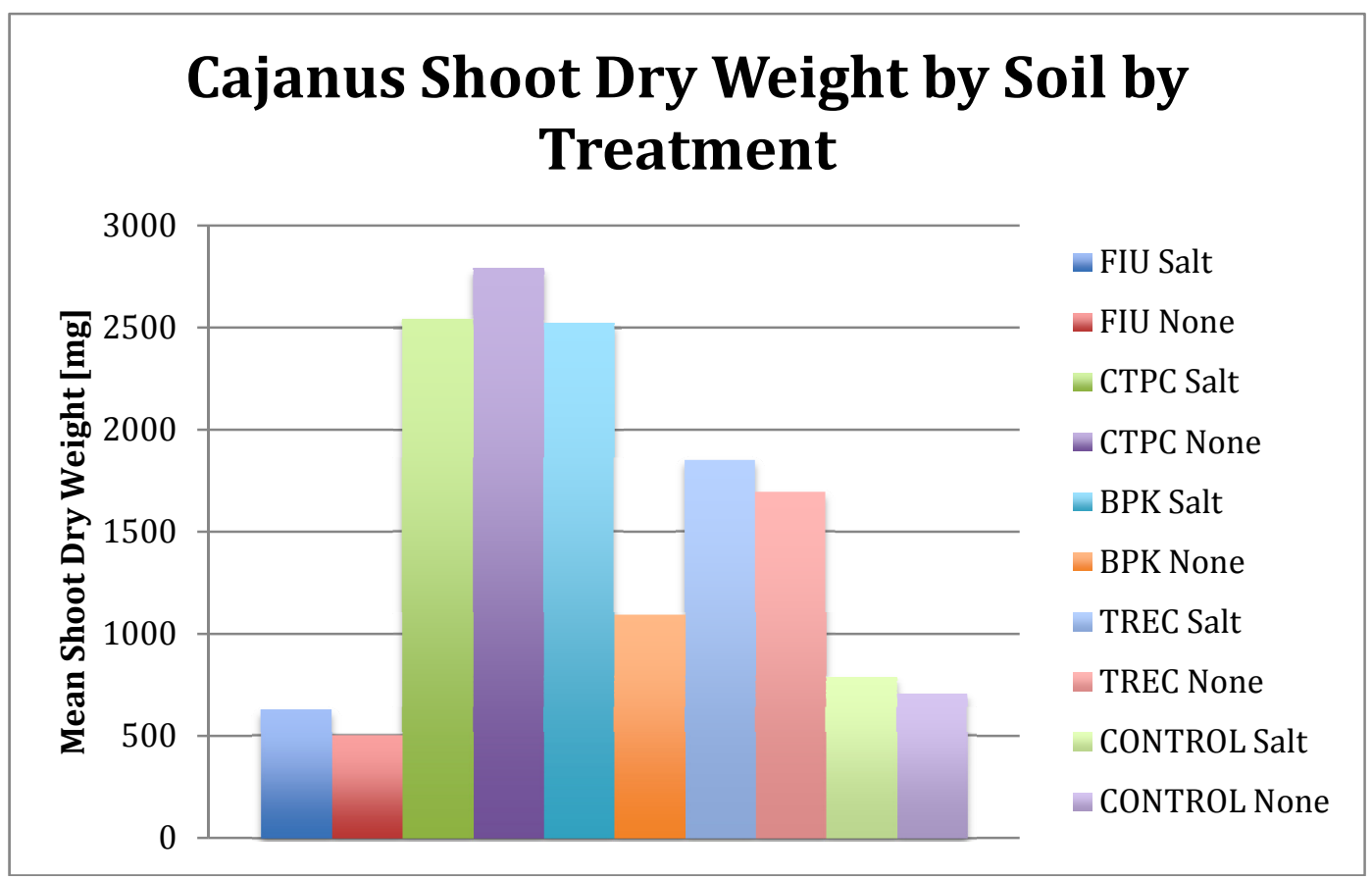

Figure 6x.

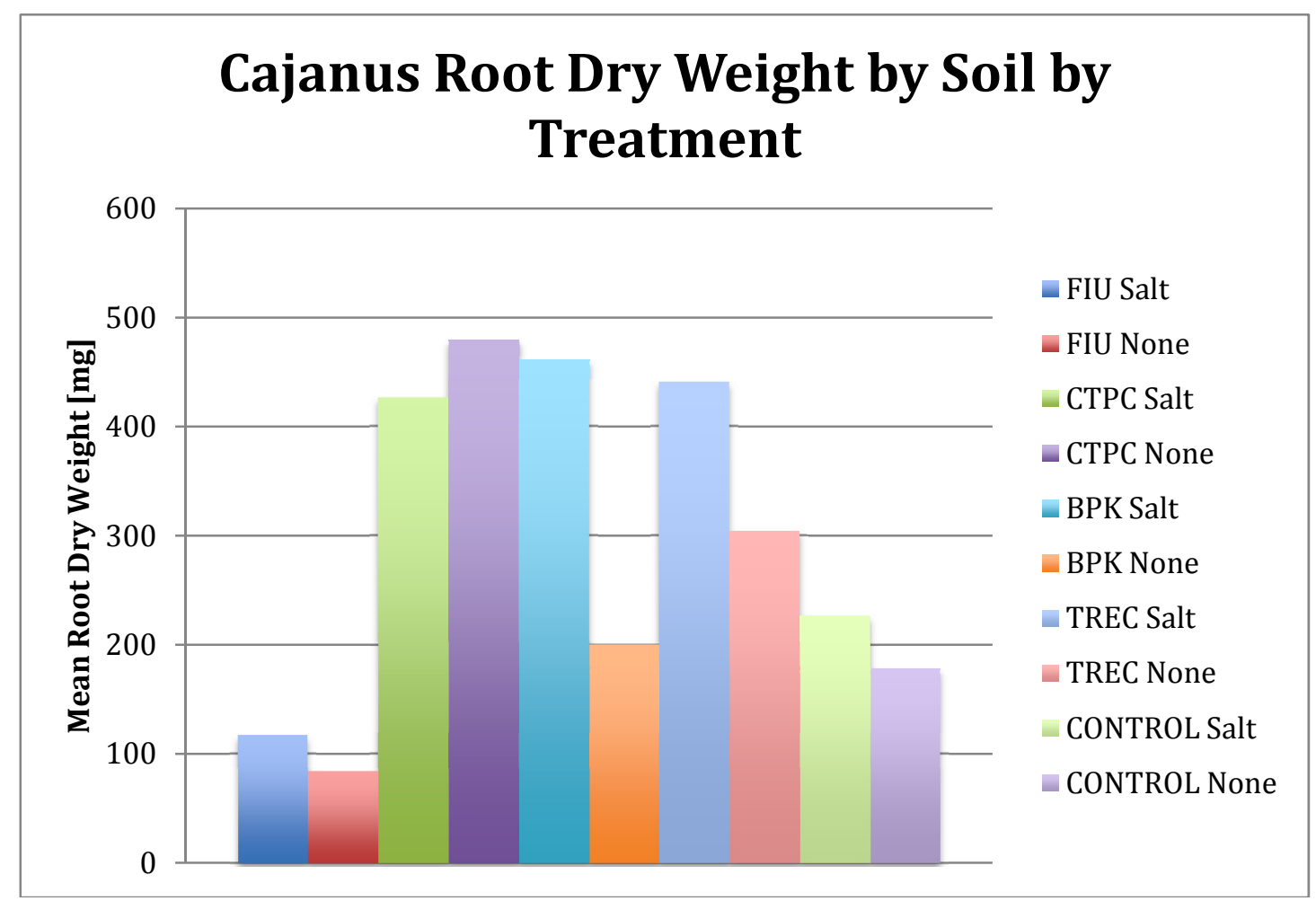

Figure 6xi. 


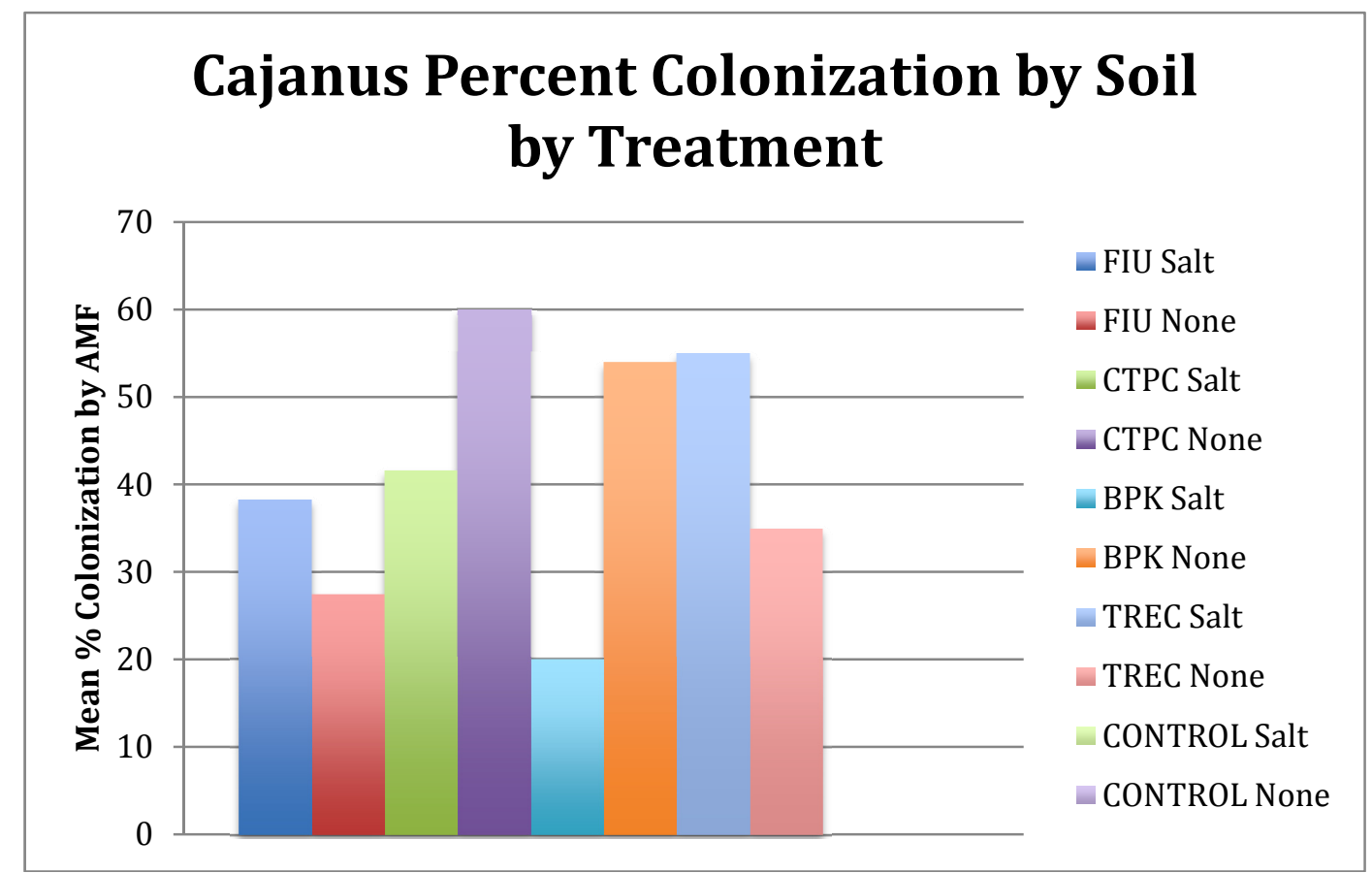

Figure 6xii.

On table 2 [second harvest], Cajanus cajan saw very consistent patterns between mean shoot biomass and mean root biomass, which is different from the variations observed with the other legume species. The highest mean shoot and root biomass was in CTPC soil, while the lowest mean shoot and root biomass was in FIU soil. All soil treatments except CTPC had higher mean shoot and root biomass in the salt treatment than the non-salt treatment. Cajanus cajan had higher mean percent colonization in the salt treatment in FIU and TREC soils than the non-salt treatment, and lower mean percent colonization in the salt treatment in CTPC and BPK soils than the non-salt treatment.

The shoot and root mean dry biomass among the treatments have some consistency in each soil type, but the variations among them may suggest plant biomass allocation in response to altered environments or salinity stress. Occasionally a large mean biomass can be due to one large plant and multiple smaller plants creating a larger average. These means nevertheless portray the general trends observed throughout the 
experiment. Overall, across the four legume species, the highest mean root and shoot dry weights were in the CTPC soil. I hypothesize that this may be a result of the fact that the shade house was at CTPC; thus, CTPC soil experienced the most similar environment in the experimental conditions to its original conditions, which may have provided a fitness advantage. Percent colonization varied among the soils as well as among the salt and non-salt treatments, and may have been influenced by initial soil sodium content, interactions between the legumes and the soil, and environmental conditions.

\section{IV-B. Differences Among Soil, Salinity Treatments, and Pot Size}

Plant growth and performance traits for the first harvest were not significantly different among treatments (Table 1). Colonization traits also did not vary substantially (Table 2), except for C. cajan. Growth and shoot sizes tended to be low on autoclaved soil, likely a consequence of removing mycorrhizae and rhizobial bacteria from plants grown on small volumes of low fertility soil. Differences in plant fitness traits among the soils were much smaller and not significant in post-hoc comparisons. I observed differences in root biomass across pot sizes, driven by small sizes of roots in the smallest pots. Salt only seemed to have a significant effect on the growth rate and shoot biomass of Cajanus cajan. This is because of the fact that the other three species, A. precatorius, C. fasciculata and T. angustissima are found in pine rocklands and have adapted to an environment that does receive occasional pulses of salinity. Cajanus cajan is likely not adapted to such salinity. An interesting further investigation would be to test the AM symbiosis with different cultivars of pigeonpea, some of which have been bred to tolerate more saline environments. 
Table 1. Differences in plant traits across different soils, salinity treatments, and pot sizes. F values are shown, with numerator and denominator $\mathrm{df}$ as subscripts. ${ }^{*} \mathrm{P}<0.05, * * \mathrm{P}<0.01, * * * \mathrm{P}<0.001$

\begin{tabular}{|c|c|c|c|c|}
\hline Species & Treatment & Growth Rate & Root Biomass & Shoot Biomass \\
\hline \multirow[t]{6}{*}{ Abrus } & Soil & 4,371 & $4,401.43$ & $4,414.60 * *$ \\
\hline & Salt & $1,372.87$ & $1,400.02$ & $1,410.09$ \\
\hline & Potsize & $2,370.32$ & $2.403 .92 \%$ & $2.413 .71 *$ \\
\hline & Soil*Salt & 4.371 .26 & $4,400.97$ & $4,400.26$ \\
\hline & Soil*potsize & 8.370 .84 & $8.402 .25 \%$ & $8.412 .38 \%$ \\
\hline & Salt*Potsize & $2,372.05$ & $2,400.22$ & $2,410.17$ \\
\hline \multirow[t]{5}{*}{ Cajanus } & Soil & $4,122.63$ & $4,111.13$ & $4,111.96$ \\
\hline & Salt & $1,124.65^{*}$ & $1,112.25$ & $1,115.68 \%$ \\
\hline & Potsize & $1,125.78 *$ & $1,110.02$ & $1,111.31$ \\
\hline & Soil*Potsize & $2,121.44$ & $1,110.66$ & $1,116.04 \%$ \\
\hline & Salt*potsize & $1,120.01$ & $1,110.45$ & $1,110.26$ \\
\hline \multirow[t]{6}{*}{ Chamaecrista } & Soil & 4.181 .33 & 4.81 .32 & $4,167.74 * *$ \\
\hline & Salt & $1,181.64$ & $1,80.29$ & $1,160.53$ \\
\hline & Potsize & $2,180.04$ & $2,80.18$ & $2,164.73 *$ \\
\hline & Soil*Salt & 4.180 .27 & $3,80.03$ & $4,160.46$ \\
\hline & Soil*Potsize & $7,180.34$ & $4,80.01$ & $5,162.03$ \\
\hline & Salt*Potsize & $2,180.02$ & $2,80.02$ & $2,160.96$ \\
\hline \multirow[t]{6}{*}{ Tephrosia } & Soil & $4,227.61 * * *$ & $4,231.72$ & 4.232 .41 \\
\hline & Salt & $1,220.70$ & $1,230.78$ & $1,230.01$ \\
\hline & Potsize & $2,225.02 *$ & $2,230.86$ & $2,231.05$ \\
\hline & Soil*Salt & $4,220.16$ & $3,230.23$ & $4,230.45$ \\
\hline & Soil*potsize & $6,220.55$ & $6,231.22$ & $6,230.66$ \\
\hline & Salt*potsize & $2,220.86$ & $2,231.49$ & $2,231.27$ \\
\hline
\end{tabular}

Table 2. Differences in colonization rate among among soils, salinity treatments, and potsizes. F values are shown, with numerator and denominator $\mathrm{df}$ as subscripts. ${ }^{*} \mathrm{P}<0.05$, $* * \mathrm{P}<0.01, * * * \mathrm{P}<0.001$, **** $\mathrm{P}<$ 0.0001

\begin{tabular}{|l|l|l|}
\hline Species & Treatment & Colonization Rate \\
\hline Abrus & Soil & $\mathbf{4 , 3 7} \mathbf{8 . 4 2} * * * *$ \\
\hline & Salt & $1,370.97$ \\
\hline & Potsize & $2,372.23$ \\
\hline & Soil*Salt & $4,371.54$ \\
\hline & Soil*potsize & 8.371 .05 \\
\hline & Salt*Potsize & $2,370.15$ \\
\hline Cajanus & Soil & $3,1110.37 * *$ \\
\hline & Salt & $\mathbf{1 , 1 1} 2.91$ \\
\hline & Potsize & $\mathbf{1 , 1 1} 1.81$ \\
\hline & Soil*Salt & $1,113.05$ \\
\hline & Soil*Potsize & $1,111.75$ \\
\hline & Salt*potsize & $1,110.11$ \\
\hline Chamaecrista & Soil & $\mathbf{3 , 7} \mathbf{7 . 7 3}$ \\
\hline & Salt & $1,70.26$ \\
\hline
\end{tabular}




\begin{tabular}{|l|l|l|}
\hline & Potsize & $2,70.36$ \\
\hline & Soil*Salt & $3,73.78$ \\
\hline & Soil*Potsize & $3,70.15$ \\
\hline & Salt*Potsize & $2,70.01$ \\
\hline Tephrosia & Soil & $\mathbf{4 , 1 4} 7.54 * *$ \\
\hline & Salt & $1,140.65$ \\
\hline & Potsize & $\mathbf{2 , 1 4} 0.61$ \\
\hline & Soil*Salt & $3,140.79$ \\
\hline & Soil*potsize & $6,141.62$ \\
\hline & Salt*potsize & $2,140.66$ \\
\hline
\end{tabular}

Colonization rate was significant relative to soil type for all four legume host species, suggesting that the soil structure/nutrient composition as well as possibly the AMF community composition within each of these soils is unique, and plays a major role in the AM symbiosis.

\section{IV-C. Diversity of Fungi By Location}

Diversity was assessed for each location, that is, each soil type, within the two studies [including FIU, CTPC, BPK, TREC and HAFB] using spore morphology. Spore morphology was used to identify spores to the genus level. Each unique spore was further described as species $1,2,3 \ldots 24$. See Fig. 7a for a map showing generic diversity of AMF in the five locations [includes the Homestead Airforce Base from the G. smallii chapter]. Spores were then analyzed based upon their different morphologies [Fig. 7b-d]. 


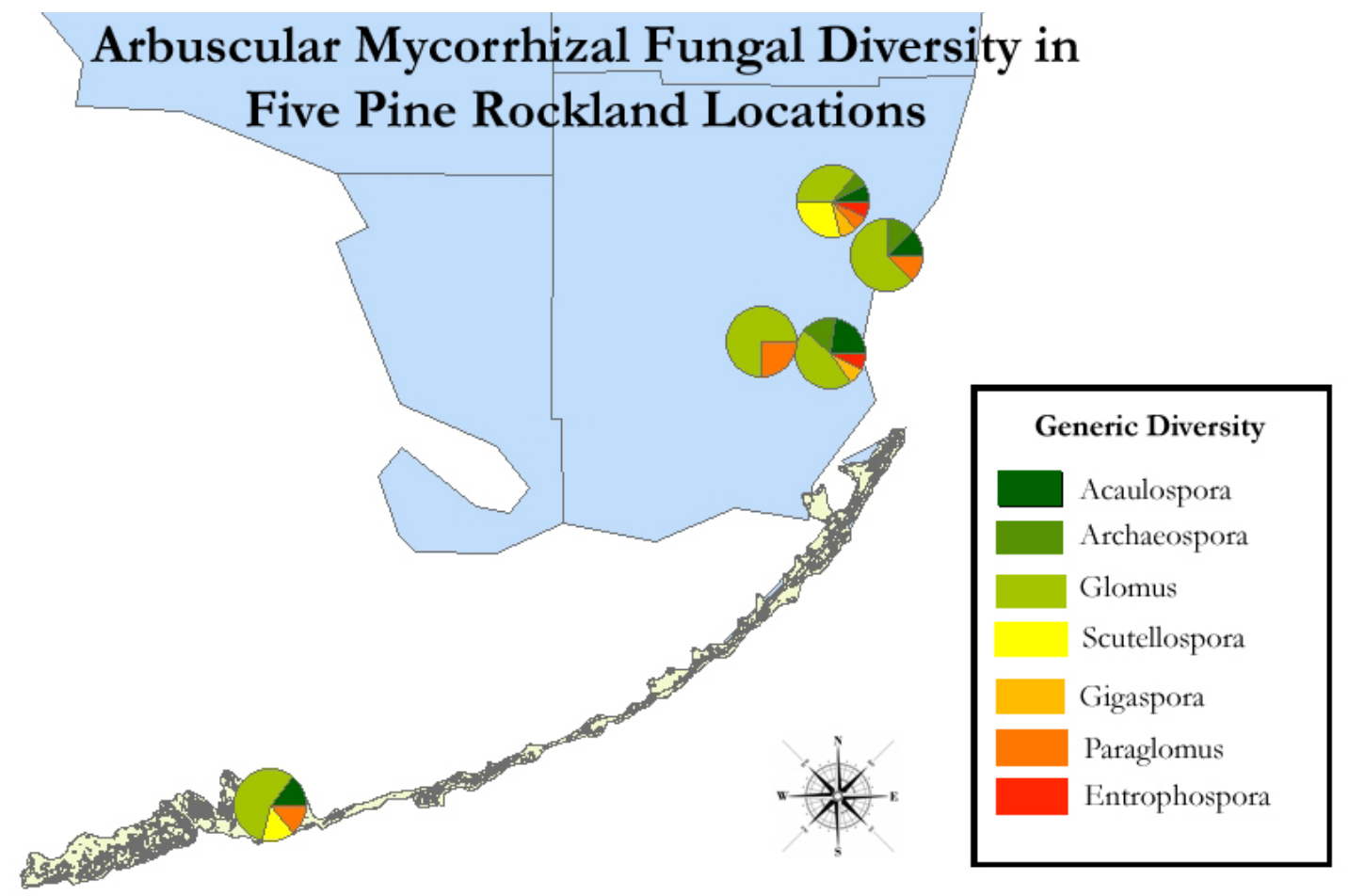

Figure 7a. Map with pie charts showing generic diversity by location, based upon spore morphology. For the four locations on the mainland, clockwise from the top FIU, CTPC, HAFB and TREC. In the Florida Keys, BPK. Glomus was the dominant genus in all five locations [Florida map from ArcGIS10:Data:USA:Counties].

In all five locations used in this thesis research [FIU, CTPC, TREC and BPK from Part 1 of the study, and HAFB from the Galactia smallii study], Glomus was the dominant genus. Glomus has long been considered the dominant genus in the Glomeromycota, as well as the most ubiquitous. Therefore, this is the expected result. TREC, considered to be the most natural and undisturbed of the pine rocklands surveyed, had the lowest generic diversity, representing only two genera, Glomus and Paraglomus. According to the Intermediate Disturbance Hypothesis (IDH), this is also the expected result, as a healthy ecosystem with low disturbance is expected to have low diversity. According to this hypothesis, a system with intermediate amounts of disturbance creates just enough species movement and competition to maximize local diversity. Once 
disturbance exceeds a certain level, diversity may drop once again (Connell 1978). The FIU pine rockland is considered to have a high level of disturbance, BPK is considered to have minimal disturbance, and CTPC and HAFB are considered to have moderate to medium levels of disturbance. If they follow expectations of the IDH, then CTPC and HAFB would have the highest diversity, followed by BPK, then FIU, having the highest disturbance, should have low diversity, like TREC. However, this is not actually the case - FIU, with the highest amount of disturbance, has the highest generic diversity [representing seven genera] based upon spore morphology. The BPK and CTPC sites, with minimal and moderate levels of disturbance, respectively, have equal generic diversity, and similar generic composition, with the only difference being between Scutellospora (BPK) and Archaeospora (CTPC). HAFB, with moderate disturbance, has higher generic diversity by one than CPTC and BPK, but lower generic diversity by two than FIU. How can this be explained by the IDH? According to IDH, species can be divided into $\mathrm{K}$-selected and $\mathrm{r}$-selected species. The $\mathrm{K}$-selected species are considered more competitive, yet persisting in an environment for a long time, whereas R-selected species are described as less competitive yet colonizing new areas quickly. The Kselected and r-selected species typically fill different niches, enabling them to coexist in an environment, thus fulfilling the IDH by maximizing species richness at an intermediate disturbance level (Catford et al. 2011). It would not typically be assumed that AMF would be occupying different niches, yet perhaps different species of AMF have developed unique strategies for survival; thus AMF at some level may be divided into K-selected and r-selected species, which would help to explain the differences in generic diversity among the sites with different levels of disturbance. For instance, FIU 
being the most disturbed, according to IDH would have low species diversity because of species migration as a consequence of outcompetition, assuming all of the AMF species occupy the same niche. However, FIU is not only a highly disturbed site - it is a recently disturbed site. Therefore, if some AMF species existed, possibly K-selected species in high diversity due to the aboveground plant diversity in the nature preserve, and a disturbance occurred, other AMF species, possibly r-selected species, would have moved in just before the time of sampling, resulting in a high generic diversity in these soil samples.

The five sites surveyed in this study [including HAFB for the Galactia chapter] comprised four different soil types. Interestingly, BPK and HAFB shared a soil type (Soil 13 (Keyvaca very gravelly loam, extremely stony)), TREC was on top of Soil 7 (Krome very gravelly loam), CTPC was on top of Soil 22 (Opalacka sand-Rock outcrop complex), and FIU was on top of Soil 10 (Udorthents; limestone substratum-urban land complex) (NRCS 2013). My hypothesis, that each pine rockland fragment would have a unique AMF diversity, was true. However, would underlying soil type play a role in AMF community similarity among sites? The question of underlying soil type could only be investigated between BPK and HAFB, as both overlay Soil 13. Soil 13 did not prove to influence AMF diversity, as BPK and HAFB had only two genera, Acaulospora and Glomus, in common, with five genera different between them. Overall, the fact that different soils supported different diversities of AMF is in support of my hypothesis, and is further supported by a recent study by Velázquez et al (2013), which demonstrated that the diversity of AMF morphotaxa among and within ecosystems is most heavily influenced by edaphic conditions. 


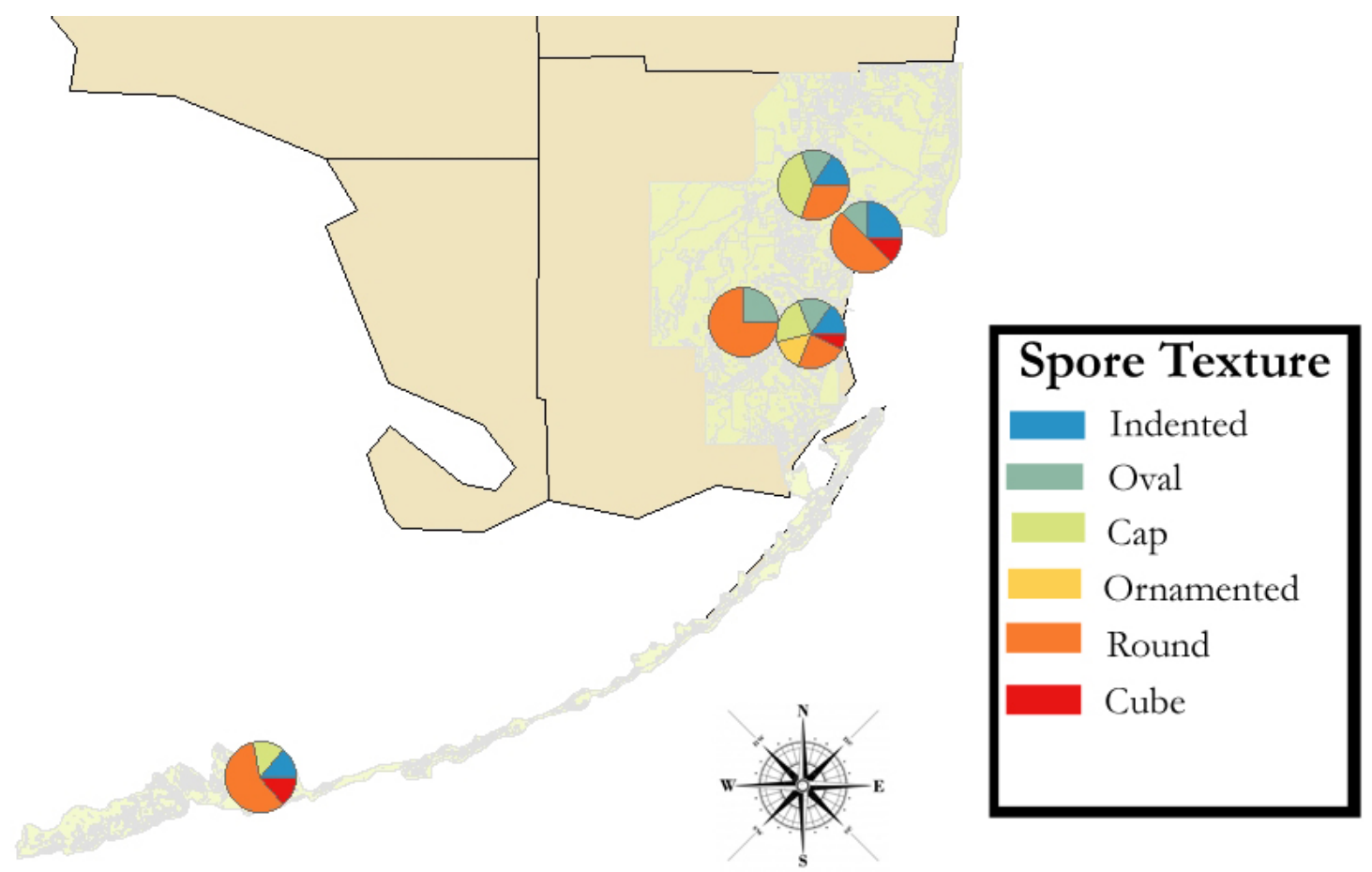

Figure 7b. Spore texture diversity by location. For the four locations on the mainland, clockwise from the top FIU, CTPC, HAFB and TREC. In the Florida Keys, BPK. HAFB experienced the highest diversity in spore texture. Round spores dominated in BPK, TREC and CTPC. 


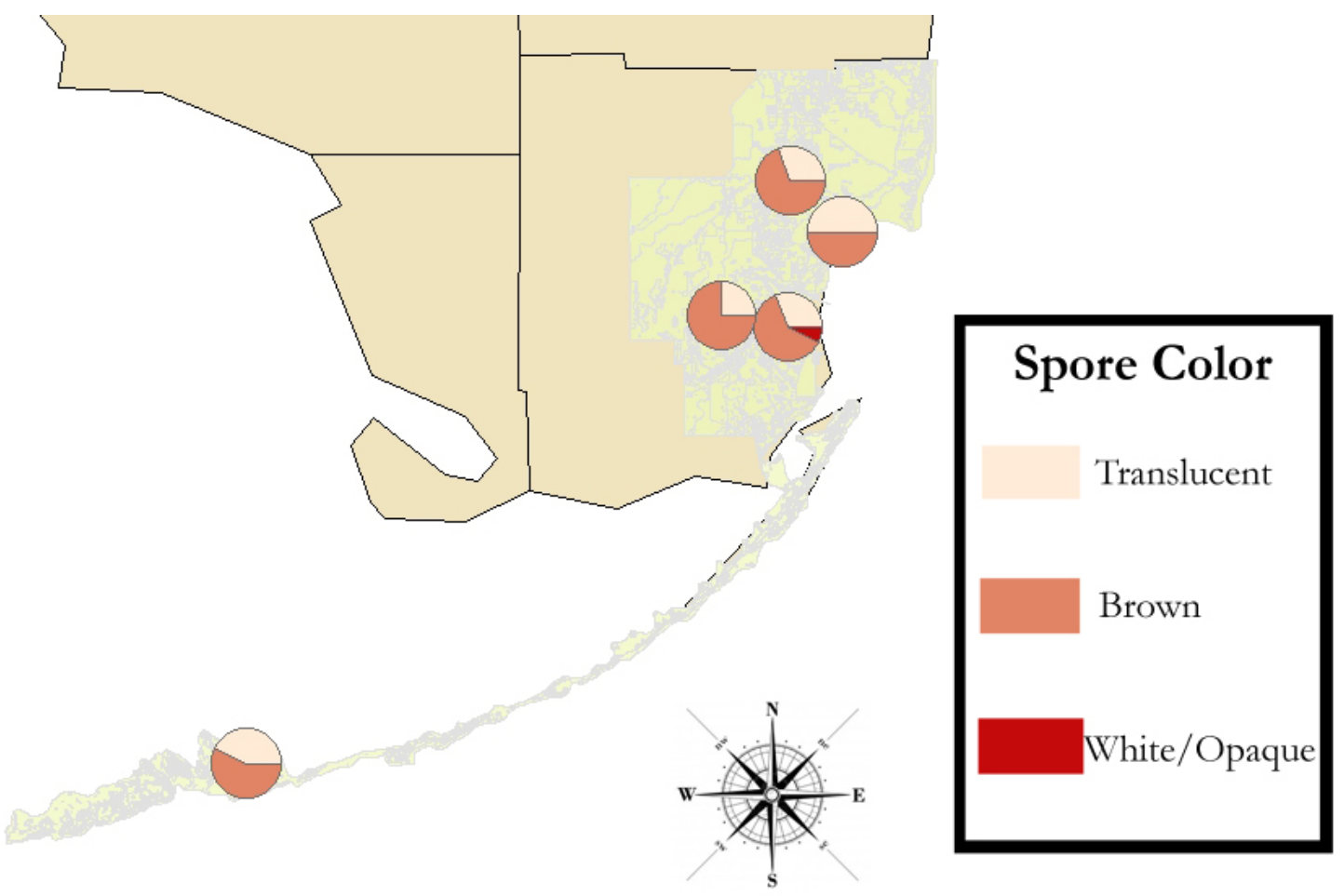

Figure 7c. Spore color diversity by location. For the four locations on the mainland, clockwise from the top FIU, CTPC, HAFB and TREC. In the Florida Keys, BPK. Brown was the dominant spore color in four of the five locations, and was in equal proportion to translucent spore color at CTPC. 


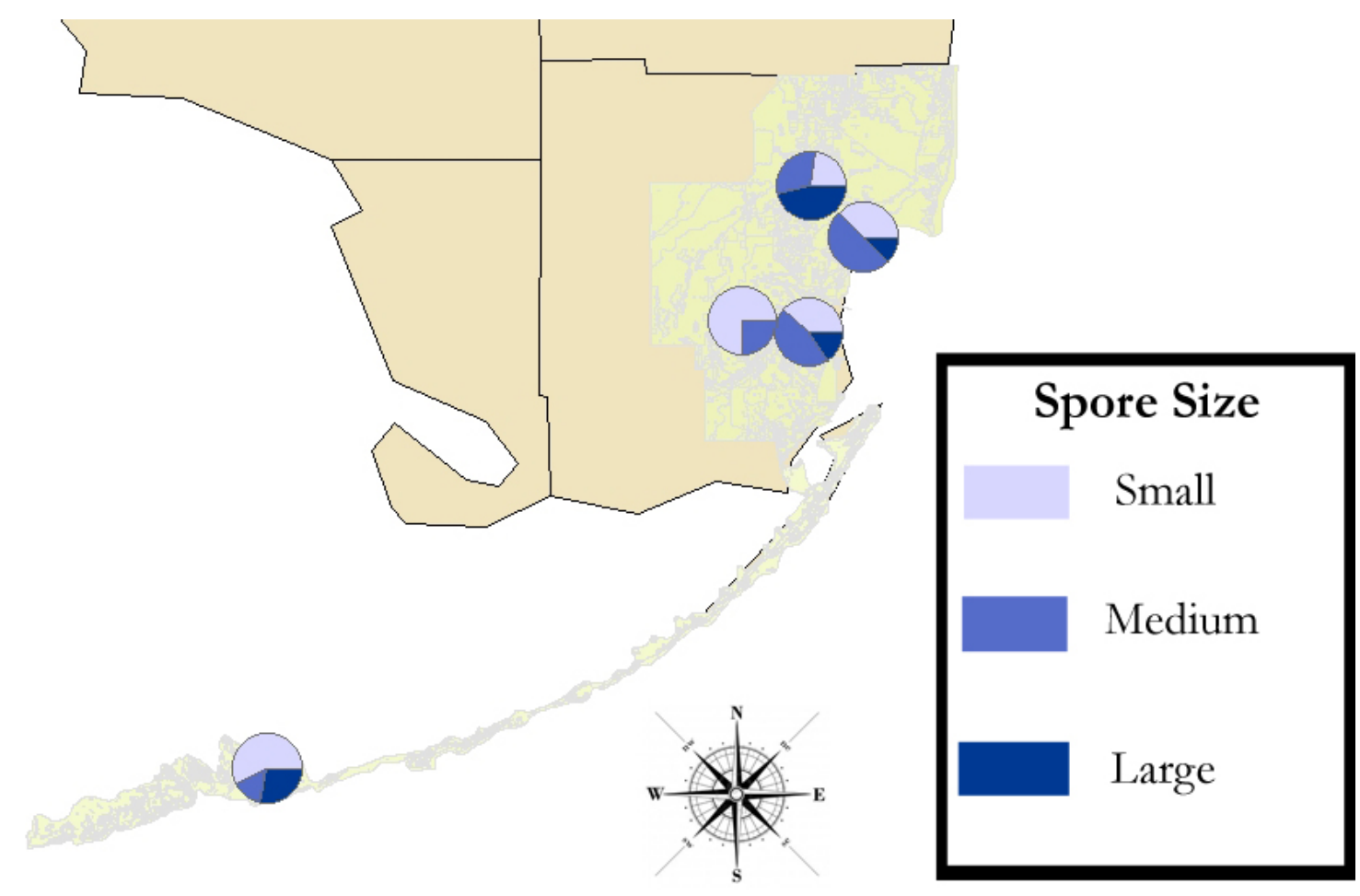

Figure 7d. Spore size diversity by location. For the four locations on the mainland, clockwise from the top FIU, CTPC, HAFB and TREC. In the Florida Keys, BPK. Small spores were dominant in BPK and TREC, then making a shift to medium spores in HAFB and CTPC, finally to large spores in FIU.

Spores were assessed not only for their generic diversity, but for their

morphological diversity among the five pine rockland sites. They were assessed based

upon their texture, color and size, in order to determine whether any of these

morphologies may dominate in an area because they are well adapted to conditions

within that area. BPK, for instance, had the highest salinity content in the soil, and was

dominated by small, brown, and round spores. However, TREC, with low salinity and

disturbance, was also dominated by small, brown and round spores. While interesting

trends can be observed within the spore morphologies - such as spore size changing from

small, through medium, to large spores as we go from southern to northern pine rockland 
sites - no conclusions can be directly made about specific morphological adaptations to each of these locations, as there are too many other variables involved.

Species diversity by location was assessed using a Shannon diversity index, which uses the proportion of one species found within total species found. The highest Shannon diversity index was in FIU soil, $\mathrm{H}=5.3012$, while TREC had the lowest Shannon diversity index, $\mathrm{H}=1.7548$. For CTPC, $\mathrm{H}=2.9257$ and for BPK, $\mathrm{H}=3.1705$ [Fig. 8].

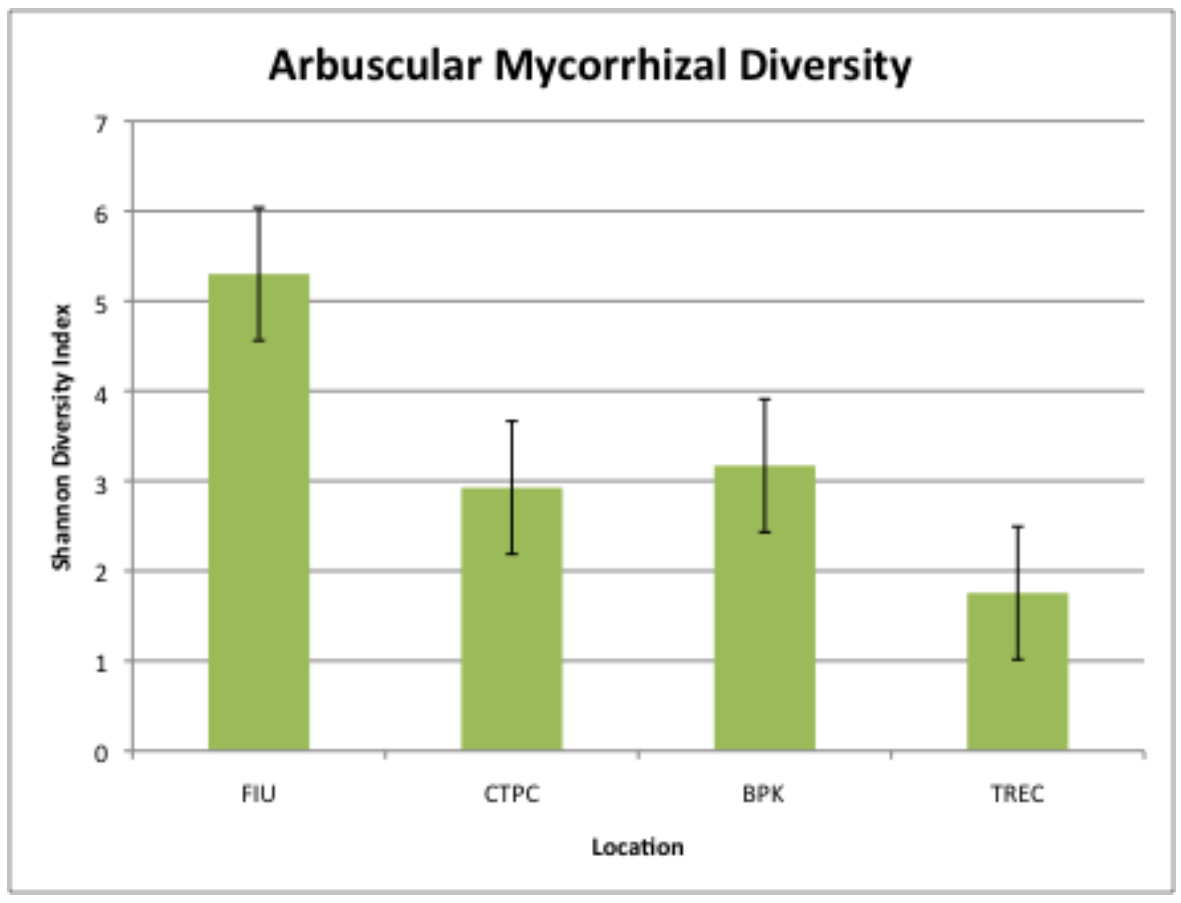

Figure 8. Shannon diversity of AMF by location.

\section{DISCUSSION}

\section{V-A. Efficacy of Arbuscular Myocrrhiza}

The fact that generic diversity determined by morphotaxa was unique in each of the four pine rockland locations sampled, and that percent colonization [proxy for AM symbiotic activity] was significantly correlated to soil type, supports the hypothesis that AMF communities would be unique in each pine rockland fragment. Each pine rockland 
fragment in south Florida hosts a unique AMF community which in turn has coevolved with its aboveground community (Saunders et al. 1991, Davison et al. 2012). Thus, not all pine rockland soil can be treated as exactly the same. The local diversity of soil biota in pine rockland fragments should be a consideration in conservation, restoration, reintroduction, connection and development decisions.

The FIU soil had both the highest Shannon diversity index as well as the highest generic diversity (representing seven genera within the Glomeromycota), supporting the idea that the highest diversity is not representative of the pine rockland with the least disturbance. In fact, healthy pine rocklands with low disturbance should be expected to have low AMF diversity.

Though AMF were shown to improve plant fitness traits between AM-plants in the four soil types and non-AM-plants in the control soil, there were not significant differences between saline and non-saline treatments in any of the four soil types or the control soil [non-AM]. Therefore no conclusions can be made about the fitness benefits conferred by AMF to their legume hosts under saline stress. It is possible that too many different variables were examined in this experiment, obscuring the potential significance of various interactions. Further investigations would include an experiment using uniform pot sizes and higher replicates for saline and non-saline treatments in order to be able to examine the effects of AMF on their host's fitness under salinity stress.

\section{V-B. Assessing Fitness of Symbiotic Partners}

In the present study, growth rate, shoot dry biomass and root dry biomass were used as proxies for plant fitness traits. Fitness can be difficult to measure and define, being the synergistic result of interacting parts rather than simple, linear measurements. 
That is why features such as biomass are used as proxies for fitness. While in other studies involving plant-AMF interactions, percent colonization is used as a proxy for fungal fitness, in this study I used percent colonization as a proxy for AM symbiont activity (Hoeksema \& Forde 2008). Though percent colonization, as well as presence/absence of vesicles, arbuscules and hyphae can provide some insight into the status of the arbuscular mycorrrhizal fungi themselves, it does not necessarily serve as a proxy for fungal fitness. I am able to investigate the AM symbiosis in a single direction; the AMF's effects upon plant fitness proxies, rather than also being able to investigate the plant's effects upon the AMF's fitness proxies. Determining fitness measurements of AMF requires further investigation, as it is an often-overlooked component of AM symbiosis research, creating a skewed perspective of the nature of the AM symbiotic relationship.

While little is known about plant fitness and how to quantify it, even less is known about fungal fitness, especially microscopic soil fungi like AMF. Percent colonization, spore count, spore mass, hyphal length and hyphal mass have all been proposed as proxy measures of AMF fitness. However, not only might these not accurately represent fungal fitness, they are also very difficult to quantify. AMF, like plants and other organisms, fill a variety of niches within their symbiotic capacity. Not only do they have unique host-specific relationships and environment-specific morphologies, they also have unique functional adaptations (Koch et al. 2012). Some AMF contribute their carbon to forming long, elaborate hyphae to explore the soil, while others invest more in storage for later. One strategy cannot necessarily be considered 
more fit than the other. Therefore much more research is needed into how to define and quantify the fitness of the partners in the AM symbiotic relationship.

\section{GALACTIA SMALLII}

Following a generous donation from researchers at the Center for Tropical Plant Conservation and Fairchild Tropical Botanic Garden of one hundred mature Galactia smallii plants, I examined the responses of Small's Milkpea (Galactia smallii), a small understory legume [Fabaceae] endemic to south Florida pine rockland ecosystems, to the AM symbiosis. Like many other endemics within the pine rocklands, it is currently listed as an endangered species, due to fragmentation and habitat loss, as well as competition from invasive species, loss of pollinators and poor management practices (Ross et al. 2009, Bibb et al. 2010, FWS(II) 2000). Habitat fragmentation may also be influencing the soil microbial community. In the species management plan for G. smallii (FTBG 2002), mutualisms are listed as "unknown" factors in their conservation and restoration management study.

In 2009, nearly 100,000 Galactia smallii individuals were observed near the Homstead Airforce Base during ongoing demographic observations (Bibb et al. 2010). Since development is planned for the base, conservation efforts are underway to protect and relocate some of these individuals. As a part of this effort, in early 2012, 500 adult plants from the Homestead Airforce Base were collected and moved into ex situ conservation at Fairchild Tropical Botanic Garden's Kushlan Institute for Tropical Science. These plants are being maintained in an open-air rare plant nursery for outbred seed collection. During the 2012 collection effort, the mature plants were dug up with some of their original soil, which was then mixed with standard potting soil before being 
placed in pots in the nursery. One hundred plants from this collection were used in the current study.

These 100 plants were grown in a shade house, which gets periodic watering from sprinklers connected to a groundwater source. For six weeks, these 100 plants received an addition (2mL per plant) of P-limited Hoagland's solution [Limited Hoagland's solution: diluted amounts of calcium, potassium, iron, magnesium sulfate, manganese chloride, copper sulfate and zinc sulfate in 1L DI water] each week. Fifty of the plants (151-200) also received a salt treatment: $4-5 \mathrm{~mL}$ of $10 \mathrm{ppm}$ saline solution using stock sodium chloride and double DI water. The salinity treatment used mimics the seasonal rise in salinity that can occur in Florida coastal pine rockland patches from salt water intrusion into the aquifer at the end of the dry season (April-June), or the rise in salinity that can occur when storm-associated salt water surges are followed by drought, as happened after hurricane Wilma in 2005 (Saha, A. et al. 2011, Saha, S. et al. 2011). The salt dosage was intended to be sub-lethal, such as would occur during a moderate salinization of the aquifer at the end of the dry season. The other fifty plants did not receive a salt treatment.

Both treatments (control and saline treatment) were made on a once per week basis for six weeks; thus, salt treated plants received six additions of saline solution (4$5 \mathrm{~mL}$ of $10 \mathrm{ppm}$ saline solution) before harvest. Inevitably, this saline treatment would wash away when the plants were watered, acting more like a pulse of saline stress rather than a constant saline stress to the AMF relationship.

After six weeks the plants were harvested. Their roots were washed with tap water, soil samples were collected from each pot, and roots and shoots were separated for weighing and quantification of associated soil microbial symbionts. Once nodules were 
counted and root tips collected for analysis, both roots and shoots were dried overnight in an $80^{*}$ drying oven, and then weighed. Root tips were collected and prepared, as above, for percent colonization analysis [Fig. 8]. Soil was also collected and prepared, as above, for spore identification and quantification. HAFB, the Homestead Airforce Base, represents the spore diversity from the Galactia smallii experiment.

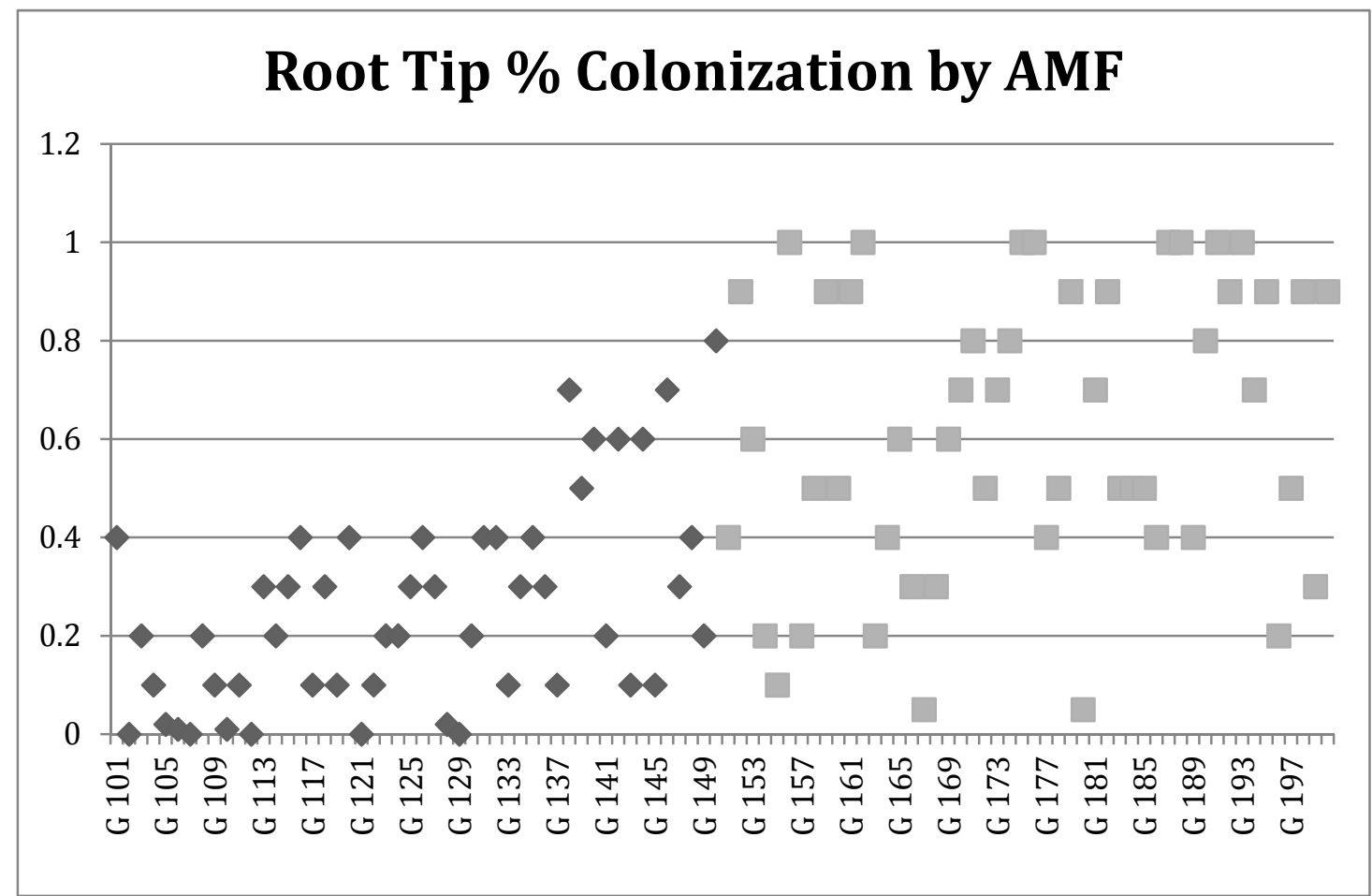

Figure 9. Percent colonization by AMF of Galactia smallii under non-saline (101-150) and saline (151-200) conditions.

On the basis of morphological observations of spores at 100x magnification, six genera within Glomeromycota were represented; Acaulospora, Gigaspora, Glomus, Paraglomus, Entrophospora, and Scutellospora. There was higher percent colonization of roots in the salt treatment group than in the untreated group (62\% vs $33 \%, \mathrm{t}=36.18, \mathrm{P}$ $<0.0001)$. However, there were not observed differences in spore count per gram (96 vs $103, \mathrm{t}=1.28, \mathrm{P}=0.44)$, number of genera present $(2.22$ vs $2.24 \mathrm{t}=0.16, \mathrm{P}=0.90)$ or diversity index $(0.369$ vs $0.373, \mathrm{t}=0.18, \mathrm{P}=0.88)$. The difference in colonization 
between the saline and non-saline treatment suggests that the changes because of the short (six week) salt treatment did not involve a shift in fungal associates, but a greater reliance on associates already present. Since these plants were acquired for this study as mature plants, it is assumed that AMF associations had already been made in the soil, thus the non-saline treatment is used as a baseline to compare the saline treatment to, in terms of AM symbiotic activity. As mentioned above, an increase in percent colonization could mean a lot of things, but for the purposes of this study it is used as a proxy for an increase in overall symbiotic activity. Therefore, the results of this study with mature Galactia smallii suggest that there is a significant overall increase in symbiotic activity with AMF in response to salinity stress. The increase in symbiotic activity could be the result of a variety of factors. It could potentially be that under saline stress, the plant needs more help acquiring nutrients, and therefore makes more associations with the AMF in its rhizosphere. Or, under saline stress, the AMF have developed mechanisms, such as increasing soluble sugars in the roots, to help plants avoid osmotic stress from the increased salinity in the environment (Feng et al. 2002). There is also a possibility that the observed increase in percent colonization is not controlled by the plant, but rather by the AMF - some AMF may act as opportunists when the plant host is in a weakened, stressed state, and increase their colonization of the plant root during this time. Salinity may even have some growth effects, positive or negative, on the AMF themselves, and they may respond to these growth effects by increasing their associations within their plant host. 


\section{SUMMARY}

While these studies do demonstrate a positive effect of AMF on their legume hosts, there is still much to be investigated regarding the mechanisms and specific interactions of the AM symbiosis. My study calls for further investigation into fitness proxies for both partners in the AM symbiosis, and emphasizes root colonization as a proxy for AM symbiosis activity. These studies (chapters III-V and VI) also support the unique community composition of AMF in pine rockland fragments, emphasizing the importance of considering the belowground as well as the aboveground community when making land management decisions. AMF can be used in agriculture to help crop plants deal with stressors such as salinity, however, I propose pairing different cultivars with different AMF communities to maximize the adaptations to different environments. 


\section{LIST OF REFERENCES}

Albrecht, C., Geurts, R. and Bisseling, T. (1999). Legume Nodulation and Mycorrhizae Formation: Two Extremes in Host Specificity Meet. The EMBO Journal 18 (2):281-288.

Amundson, R., Guo, Y. and Gong, P. (2003). Soil Diversity and Land Use in the United States. Ecosystems 6:470-482.

Audet, P. and Charest, C. (2010). Identification of Constraining Experimental Design

Factors in Mycorrhizal Pot-Growth Studies. Journal of Botany 2010:1-6.

Babikova, C., Gilbert, L., Bruce, T.J.A., Birkett, M., Caulfield, J.C., Woodcock, C., Pickett, J.A. and Johnson, D. (2013). Underground Signals Carried Through Common Mycelial Networks Warn Neighboring Plants of Aphid Attack. Ecology Letters DOI: $10.1111 /$ ele. 12115

Bibb, K., Knight, M. and Salvato, M. (2010). Small's Milkpea (Galactia smallii) 5-Year Review: Summary and Evaluation. U.S. Fish and Wildlife Service 1-15.

Bonfante, P. and Genre, A. (2008). Plants and Arbuscular Mycorrhizal Fungi: An Evolutionary-Developmental Perspective. Trends in Plant Science 13 (9):492-498.

Bonfante, P. and Genre, A. (2010). Mechanisms Underlying Beneficial Plant-Fungus Interactions in Mycorrhizal Symbiosis. Nature Communications DOI:

$10.1038 /$ ncomms 1046

Cardoso, I.M. and Kuyper, T.W. (2006). Mycorrhizas and Tropical Soil Fertility. Agriculture, Ecosystems and Environment 116:72-84.

Catford, J.A., Daehler, C.C., Murphy, H.T., Sheppard, A.W., Hardesty, B.D., Westcott, D.A., Rejmánek, M., Bellingham, P.J., Pergl, J., Horvitz, C.C. and Hulme, P.E. (2012). The Intermediate Disturbance Hypothesis and Plant Invasions: Implications for Species Richness and Management. Perspectives in Plant Ecology, Evolution and Systematics 14 (3):231-241.

Chalk, P.M., Souza, R. de F., Urquiaga, S., Alves, B.J.R. and Boddey, R.M. (2006). The Role of Arbuscular Mycorrhiza in Legume Symbiotic Performance. Soil Biology and Biochemistry 38:2944-2951.

Connell, J.H. (1978). Diversity in Tropical Rain Forests and Coral Reefs. Science 199:1302-1310.

Daei, G., Ardekani, M.R., Rejali, F., Teimuri, S. and Miransari, M. (2009). Alleviation of Salinity Stress on Wheat Yield, Yield Components, and Nutrient Uptake Using 
Arbuscular Mycorrhizal Fungi Under Field Conditions. Journal of Plant Physiology 166:617-625.

Davison, J., Öpik, M., Zobel, M., Vasar, M., Metsis, M. and Moora, M. (2012). Communities of Arbuscular Mycorrhizal Fungi Detected in Forest Soil Are Spatially Heterogeneous but Do Not Vary Throughout the Growing Season. PLoS ONE 7 (8):e41938.

Denison, R.F. and Kiers, E.T. (2011). Life Histories of Symbiotic Rhizobia and Mycorrhizal Fungi. Current Biology 21:R775-R785.

DERM, Department of Environmental Resources Management. (2004). Miami-Dade County Natural Areas Management Plan: Pine Rocklands. Technical Report Number 2004-1.

Doran, J.W. and Zeiss, M.R. (2000). Soil Health and Sustainability: Managing the Biotic Component of Soil Quality. Applied Soil Ecology 15:3-11.

Douds Jr., D.D. and Millner, P.D. (1999). Biodiversity of Arbuscular Mycorrhizal Fungi in Agroecosystems. Agriculture, Ecosystems and Environment 74:77-93.

Entry, J.A., Rygiewicz, P.T., Watrud, L.S. and Donnelly, P.K. (2002). Influence of Adverse Soil Conditions on the Formation and Function of Arbuscular Mycorrhizas. Advances in Environmental Research 7:123-138.

Ercolin, F. and Reinhardt, D. (2011). Successful Joint Ventures of Plants: Arbuscular Mycorrhiza and Beyond. Trends in Plant Science 16 (7):356-362.

Estrada, B., Barea, J.M., Aroca, R. and Ruiz-Lozano, J.M. (2012). A Native Glomus intraradices Strain from a Mediterranean Saline Area Exhibits Salt Tolerance and Enhanced Symbiotic Efficiency with Maize Plants Under Salt Stress Conditions. Plant Soil DOI 10.1007/s11104-012-1409-y

Feddermann, N., Finlay, R., Boller, T. and Elfstrand, M. (2010). Functional Diversity in Arbuscular Mycorrhiza - the Role of Gene Expression, Phosphorus Nutrition and Symbiotic Efficiency. Fungal Ecology 3:1-8.

Feng, G., Zhang, F.S., Li, X.L., Tian, C.Y., Tang, C. and Rengel, Z. (2002). Improved Tolerance of Maize Plants to Salt Stress by Arbuscular Mycorrhiza is Related to Higher Accumulation of Soluble Sugars in Roots. Mycorrhiza 12:185-190.

Fisher, J. and Jayachandran, K. (2002). Arbuscular Mycorrhizal Fungi Enhance Seedling Growth in Two Endangered Plant Species from South Florida. International Journal of Plant Science 163 (4):559-566. 
Friesen, M.L., Porter, S.S., Stark, S.C., von Wettberg, E.J., Sachs, J.L. and MartinezRomero, E. (2011). Microbially Mediated Plant Functional Traits. Annual Review of Ecology, Evolution and Systematics 42:23-46.

FTBG (2002) Institute for Regional Conservation, Fairchild Tropical Garden. Conservation Action Plan - Galactia smallii

FWS, U.S. Fish and Wildlife Service (I). (2000). Multi-Species Recovery Plan for South Florida: Pine Rocklands. 3:161-194.

FWS, U.S. Fish and Wildlife Service (II). (2000). Multi-Species Recovery Plan for South Florida: Small's Milkpea. 4:1023-1034.

Gosling, P., Hodge, A., Goodlass, G. and Bending, G.D. (2006). Arbuscular Mycorrhizal Fungi and Organic Farming. Agriculture, Ecosystems and Environment 113:17-35.

Hammer, E.C. and Rillig, M.C. (2011). The Influence of Different Stresses on Glomalin Levels in an Arbuscular Mycorrhizal Fungus - Salinity Increases Glomalin Content. PLoS ONE 6 (12):e28426.

Hausmann, N.T. and Hawkes, C.V. (2009). Plant Neighborhood Control of Arbuscular Mycorrhizal Community Composition. New Phytologist 183:1188-1200.

Hildebrandt, U., Regvar, M. and Bothe, H. (2007). Arbuscular Mycorrhiza and Heavy Metal Tolerance. Phytochemistry 68 (1):139-146.

Hoeksema, J.D. and Forde, S.E. (2008). A Meta-Analysis of Factors Affecting Local Adaptation between Interacting Species. The American Naturalist 171 (3):275-290.

Janos, D.P. (2011). Personal Correspondence regarding experimental design for maximizing capture of arbuscular mycorrhizal fungi in a greenhouse.

Jayachandran, K. and Fisher, J. (2008). Arbuscular Mycorrhizae and their Role in Plant Restoration in Native Ecosystems. Mycorrhizae: Sustainable Agriculture and Forestry. Springer 195-209.

Juniper, S. and Abbott, L. (1993). Vesicular-Arbuscular Mycorrhizas and Soil Salinity. Mycorrhiza 4:45-57.

Kaschuk, G., Leffelaar, P.A., Giller, K.E., Alberton, O., Hungria, M. and Kuyper, T.W. (2010). Responses of Legumes to Rhizobia and Arbuscular Mycorrhizal Fungi: A MetaAnalysis of Potential Photosynthate Limitation of Symbiosis. Soil Biology and Biochemistry 42:125-127. 
Kaspari, M. and Yanoviak, S.P. (2009). Biogeochemistry and the Structure of Tropical Brown Food Webs. Ecology 90 (12):3342-3351.

Kiers, E.T., Duhamel, M., Beesetty, Y., Mensah, J.A., Franken, O., Verbruggen, E., Fellbaum, C.R., Kowalchuk, G.A., Hart, M.M., Bago, A., Palmer, T.M., West, S.A., Vandenkoornhuyse, P., Jansa, J. and Bücking, H. (2011). Reciprocal Rewards Stabilize Cooperation in the Mycorrhizal Symbiosis. Science 333:880-882.

Kivlin, S.N., Hawkes, C.V. and Treseder, K.K. (2011). Global Diversity and Distribution of Arbuscular Mycorrhizal Fungi. Soil Biology and Biochemistry 43:2294-2303.

Khan, M.H., Meghvansi, M.K., Panwar, V., Gogoi, H.K. and Singh, L. (2010). Arbuscular Mycorrhizal Fungi-Induced Signaling in Plant Defense Against Phytopathogens. Journal of Phytology 2 (7):53-69.

Klironomos, J.N. (2003). Variation in Plant Response to Native and Exotic Arbuscular Mycorrhizal Fungi. Ecology 84 (9):2292-2301.

Koch, A.M., Antunes, P.M. and Klironomos, J.N. (2012). Diversity Effects on Productivity are Stronger Within than Between Trophic Groups in the Arbuscular Mycorrhizal Symbiosis. PLoS ONE 7 (5):e36950.

Krüger, M., Stockinger, H., Krüger, C. and Schüßler, A. (2009). DNA-based Species Level Detection of Glomeromycota: One PCR Primer Set for All Arbuscular Mycorrhizal Fungi. New Phytologist 183:212-223.

Latef, A.A.H.A. and Chaoxing, H. (2011). Effect of Arbuscular Mycorrhizal Fungi on Growth, Mineral Nutrition, Antioxidant Enzymes Activity and Fruit Yield of Tomato Grown Under Salinity Stress. Scientia Horticulturae 127:228-233.

Lodge, T.E. (2010). The Everglades Handbook; Understanding the Ecosystem. Pinelands. CRC Press 77-82.

Maillet, F., Poinsot, V., André, O., Puech-Pagès, V., Haouy, A., Gueunier, M., Cromer, L., Giraudet, D., Formey, D., Niebel, A., Martinez, E.A., Driguez, H., Bécard, G. and Dénarié, J. (2011). Fungal Lipochitooligosaccharide Symbiotic Signals in Arbuscular Mycorrhiza. Nature 469:58-64.

Margulis, L. and Sagan, D. (1986). Microcosmos: Four Billion Years of Microbial Evolution. University of California Press.

Maschinski, J., Ross, M.S., Liu, H., O’Brien, J., von Wettberg, E.J. and Haskins, K.E. (2011). Sinking Ships: Conservation Options for Endemic Taxa Threatened by Sea Level Rise. Climatic Change 107:147-167. 
Maschinski, J. (2013). The Connect to Protect Network: Pine Rockland Corridor Project, Benefits of Using Natives in Landscapes. Fairchild Tropical Botanic Garden Brochure.

Miransari, M. (2011). Interactions Between Arbuscular Mycorrhizal Fungi and Soil Bacteria. Applied Microbiology and Biotechnology 89:917-930.

Mortimer, P.E., Pérez-Fernández, M.A., Valentine, A.J. (2008). The Role of Arbuscular Mycorrhizal Colonization in the Carbon and Nutrient Economy of the Tripartite Symbiosis with Nodulated Phaseolus vulgaris. Soil Biology and Biochemistry 40:10191027.

NRCS, United States Department of Agriculture Natural Resources Conservation Service. (2013). Soil Data for ArcGIS10. http://soildatamart.nrcs.usda.gov

Oláh, B., Brière, C., Bécard, G., Dénarié, J. and Gough, C. (2005). Nod Factors and a Diffusable Factor from Arbuscular Mycorrhizal Fungi Stimulate Lateral Root Formation in Medicago trunculata via the DMI1/DMI2 Signaling Pathway. The Plant Journal 44:195-207.

Possley, J., Woodmansee, S.W. and Maschinski, J. (2008). Patterns of Plant Composition in Fragments of Globally Imperiled Pine Rockland Forest: Effects of Soil Type, Recent Fire Frequency, and Fragment Size. Natural Areas Journal 28 (4):379-394.

Rillig, M.C., Ramsey, P.W., Morris, S. and Paul, E.A. (2003). Glomalin, an Arbuscular Mycorrhizal Fungal Soil Protein, Responds to Land-Use Change. Plant and Soil 253:293299.

Rillig, M.C., Lutgen, E.R., Ramsey, P.W., Klironomos, J.K., Gannon, J.E. (2005). Microbiota Accompanying Different Arbuscular Mycorrhizal Fungal Isolates Influence Soil Aggregation. Pedobiologia 49:251-259.

Ross, M.S. and O'Brien, J.J. (1994). Sea-Level Rise and the Reduction in Pine Forests in the Florida Keys. Ecological Applications 4 (1):144-156.

Ross, M.S., O'Brien, J.J., Ford, R.G., Zhang, K. and Morkill, A. (2009). Disturbance and the Rising Tide: The Challenge of Biodiversity Management on Low-Island Ecosystems. Frontiers in Ecology and the Environment 7 (9):471-478.

Sah, S., Reed, S., Jayachandran, K., Dunn, C. and Fisher, J.B. (2006). The Effect of Repeated Short-term Flooding on Mycorrhizal Survival in Snap Bean Root. HortScience 41 (3):598-602.

Saha, S., Bradley, K., Ross, M.S., Hughes, P., Wilmers, T., Ruiz, P.L. and Bergh C. (2011). Hurricane effects on subtropical pine rocklands of the Florida Keys. Climatic Change DOI: 10.1007/s10584-011-0081-1. 
Saha, A., Saha, S., Sadle, J., Jiang, J., Ross, M.S., Price, R., Sternberg, L. and Wendelberger, K. (2011). Sea level rise and south Florida coastal forests. Climatic Change 107 (1):81-108.

Sanders, I.R. (2003). Preference, Specificity and Cheating in the Arbuscular Mycorrhizal Symbiosis. TRENDS in Plant Science 8 (4):143-145.

Saunders, D.A., Hobbs, R.J. and Margules, C.R. (1991). Biological Consequences of Ecosystem Fragmentation: A Review. Conservation Biology 5 (1):18-32.

Scheublin, T.R. and van der Heijden, M.G.A. (2006). Arbuscular Mycorrhizal Fungi Colonize Nonfixing Root Nodules of Several Legume Species. New Phytologist 172:732738.

Schüßler, A., Schwarzott, D. and Walker, C. (2001). A New Fungal Phylum, the Glomeromycota: Phylogeny and Evolution. Mycological Research 105 (12):1413-1421.

Snyder, J.R., Ross, M.S., Koptur, S. and Sah, J.P. (2005). Developing Ecological Criteria for Prescribed Fire in South Florida Pine Rockland Ecosystems. USGS OF 2006-1062:1109.

Sprent, J.I. and James, E.K. (2007). Legume Evolution: Where do Nodules and Mycorrhizas Fit In? Plant Physiology 144:575-581.

Syrkorová, Z., Ineichen, K., Weimken, A. and Redecker, D. (2007). The Cultivation Bias: Different Communities of Arbuscular Mycorrhizal Fungi Detected in Roots from the Field, From Bait Plants Transplanted to the Field, and From a Greenhouse Trap Experiment. Mycorrhiza 18:1-14.

Tarkka, M.T. and Frey-Klett, P. (2008). Ed. A. Varma. Mycorrhiza Helper Bacteria. Mycorrhiza, Springer-Verlag Berlin Heidelberg 113-132.

Treseder, K.K. and Cross, A. (2006). Global Distributions of Arbuscular Mycorrhizal Fungi. Ecosystems 9:305-316.

Varshney, R.K., Chen, W., Li, Y., Bharti, A.K., Saxena, R.K., Schleuter, J.A., Donoghue, M.T., Azam, S., Fan, G., Whaley, A.M., Farmer, A.D., Sheridan, J., Iwata, A., Tuteja, R., Penmetsa, R.V., Wu, W., Upadhyaya, H.D., Yang, S.P., Shah, T., Saxena, K.B., Michael, T., McCombie, W.R., Yang, B., Zhang, G., Yang, H., Wang, J., Spillane, C., Cook, D.R., May, G.D., Xu, X. and Jackson, S.A. (2011). Draft Genome Sequence of Pigeonpea (Cajanus cajan), an Orphan Legume Crop of Resource-Poor Farmers. Nature Biotechnology 30 (1):83-89. 
Velázquez, M.S., Cabello, M.N. and Barrera, M. (2013). Composition and Structure of Arbuscular-Mycorrhizal Communities in El Palmar National Park, Argentina. Mycologia 105 (3):509-520.

Vierheilig, H., Schweiger, P. and Brundrett, M. (2005). An Overview of Methods for the Detection and Observation of Arbuscular Mycorrhizal Fungi in Roots. Physiologia Plantarum 125:393-404.

Wehner, J., Antunes, P.M., Powell, J.R., Mazukatow, J. and Rillig, M.C. (2010). Plant Pathogen Protection by Arbuscular Mycorrhizas: A Role for Fungal Diversity?

Pedobiologia 53:197-201.

Yao, Q., Gao, J-L., Zhu, H-H., Long, L-K., Xing, Q-X. and Chen, J-Z. (2010). Evaluation of the Potential of Trap Plants to Detect Arbuscular Mycorrhizal Fungi Using Polymerase Chain Reaction-Denaturing Gradient Gel Electrophoresis Analysis. Soil Science \& Plant Nutrition 56 (2):205-211. 